MECHANISMS IN ENDOCRINOLOGY

\title{
Nutrition as a mediator of oxidative stress in metabolic and reproductive disorders in women
}

\section{Evanthia Diamanti-Kandarakis ${ }^{1}$, Olga Papalou ${ }^{1}$, Eleni A Kandaraki ${ }^{2}$ and Georgia Kassi²}

'Department of Endocrinology and Diabetes Center of Excellence, EUROCLINIC, Athens, Greece and ${ }^{2}$ Endocrine Unit, 3rd Department of Internal Medicine, University of Athens Medical School, Athens, Greece
Correspondence

should be addressed

to E Diamanti-Kandarakis

Email

e.diamanti.kandarakis@

gmail.com

\begin{abstract}
Nutrition can generate oxidative stress and trigger a cascade of molecular events that can disrupt oxidative and hormonal balance. Nutrient ingestion promotes a major inflammatory and oxidative response at the cellular level in the postprandial state, altering the metabolic state of tissues. A domino of unfavorable metabolic changes is orchestrated in the main metabolic organs, including adipose tissue, skeletal muscle, liver and pancreas, where subclinical inflammation, endothelial dysfunction, mitochondrial deregulation and impaired insulin response and secretion take place. Simultaneously, in reproductive tissues, nutrition-induced oxidative stress can potentially violate delicate oxidative balance that is mandatory to secure normal reproductive function. Taken all the above into account, nutrition and its accompanying postprandial oxidative stress, in the unique context of female hormonal background, can potentially compromise normal metabolic and reproductive functions in women and may act as an active mediator of various metabolic and reproductive disorders.
\end{abstract}

\section{Introduction}

Oxidative metabolism and redox homeostasis have been gradually highlighted as an integral part of aerobic life (1). Living organisms cannot exist without oxygen; yet under unfavorable cellular conditions, oxygen derivatives can interrupt oxidative equilibrium; damage proteins, lipids and nucleic acids; and compromise cell viability (2). Hence, oxidative stress was introduced to define the imbalance between excessive formation of oxidants in the presence of limited antioxidant defenses in the human body (3).

There is an increasing body of evidence showing that oxidative stress lies in the pathophysiological core of a plethora of human diseases $(4,5,6)$. However, even under physiological conditions, normal functions of human body, such as nutrition, can potentially generate oxidative stress. Macronutrients can be inflammatory and possibly

\section{Invited Author's profile}

Dr Evanthia Diamanti-Kandarakis is a Professor of Internal Medicine - Endocrinology and Metabolism and the Chairman of the Department of Endocrinology and Diabetes Center of Excellence, EUROCLINIC, Athens, Greece. Her research interests have focused for the last 25 years on clinical, molecular and environmental aspects of metabolic and reproductive abnormalities in polycystic ovarian syndrome.

() 2017 European Society of Endocrinology Printed in Great Britain
Published by Bioscientifica Ltd. 
pro-oxidant (7). A new term - nutritional or postprandial oxidative stress - has been introduced to describe the postprandial state of imbalance between the pro-oxidant load and the antioxidant defense as a consequence of excess or of inadequate supply with nutrients (8). Postprandial oxidative stress has been closely linked to subclinical inflammation and endothelial dysfunction and therefore could be involved in the pathophysiology of various metabolic and reproductive disturbances $(9,10)$.

\section{Elements of fundamentals of oxidative metabolism}

There are two main classes of free radicals or oxidants: reactive oxygen species (ROS) and reactive nitrogen species (RNS). ROS derive from molecular oxygen, formed upon incomplete reaction of oxygen, including superoxide anion $\left(\mathrm{O}_{2}^{-}\right)$, hydroxyl radical $\left(\mathrm{OH}^{-}\right)$and singlet oxygen and hydrogen peroxide $\left(\mathrm{H}_{2} \mathrm{O}_{2}\right)(11)$. This activation takes place via different cellular processes (Fig. 1) (12). However, mitochondria are considered to be the principal source of ROS. Specifically, in the mitochondrial electron transport chain (ETC), there is a tendency for an electron to directly pass to oxygen, generating eventually superoxide $\left(\mathrm{O}_{2}^{-}\right)(13)$.

RNS are a family of chemical compounds that derive from nitric oxide (NO) (14). Physiologically, NO is synthesized from L-arginine, via the catalytic action of nitric oxide synthase (NOS) and under the presence of catalytic cofactors, tetrahydrobiopterin (BH4), flavin adenine dinucleotide and flavin mononucleotide (FMN) (15). Under certain stimuli, NO reacts with superoxide
$\left(\mathrm{O}_{2}^{-}\right)$generating peroxynitrite $\left(\mathrm{ONOO}^{-}\right)$, which is believed to be one of the most toxic RNS produced in human body and can further promote the production of other forms of RNS, such as nitrogen dioxide $\left(\cdot \mathrm{NO}_{2}\right)$ and dinitrogen trioxide $\left(\mathrm{N}_{2} \mathrm{O}_{3}\right)$ (16).

In addition to the above mentioned pro-oxidants, other molecules that have also been acknowledged to share truly pro-oxidant and inflammatory properties are AGEs. AGEs, or glycotoxins, constitute a heterogenous group of more than 20 different compounds, derived from endogenous nonenzymatic glycation of macromolecules, as well as from absorbed exogenous sources (17). Upon their formation, AGEs promote ROS and RNS formation, via multiple mechanisms (18). Binding of AGEs to their multiligand receptor for advanced glycation end products (RAGE) activates NF-kB, which in turn leads to increased ROS generation, as well as to the activation of NADPH oxidase $(19,20)$.

Antioxidants are the opposing force of human body to maintain oxidative equilibrium (Fig. 2) (21). They can be divided into two major categories: enzymatic and nonenzymatic. Enzymatic antioxidants constitute innate, key enzymes that can detoxify excessive ROS and RNS, including superoxide dismutase (SOD), catalase (CAT) and glutathione peroxidase (GPx) (22), whereas nonenzymatic antioxidants are exogenous and endogenous molecules, such as glutathione, thioredoxin, vitamin $\mathrm{C}$, vitamin $\mathrm{A}$, vitamin E, selenium (Se) and zinc (Zn), used to terminate pro-oxidants $(13,23)$.

When overproduction of free radicals cannot be compensated by the powerful antioxidant defense system of the body, oxidative stress dominates (24) and

\section{Pathways of ROS/RNS production and clearance}

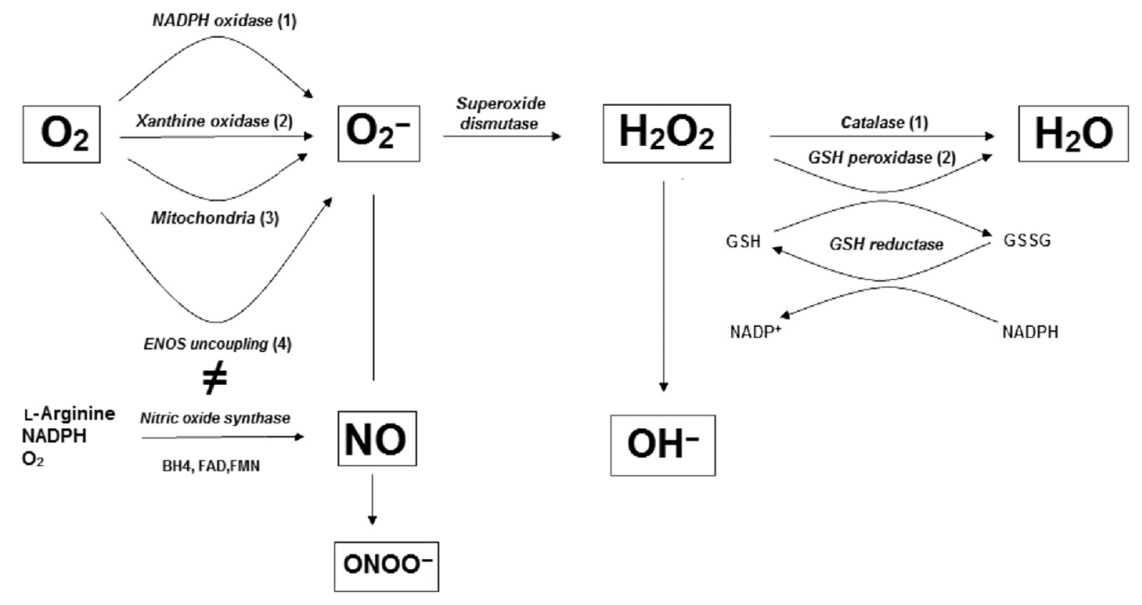

\section{Figure 1}

Molecular pathways of ROS and RNS production and clearance via different enzymatic reactions (BH4, tetrahydrobiopterin; ENOS endothelial nitric oxide synthase; FAD, flavin adenine dinucleotide; FMN, flavin mononucleotide; $\mathrm{GSH}$, glutathione; GSSG, glutathione disulfide; $\mathrm{H}_{2} \mathrm{O}_{2}$, hydrogen peroxide; NADPH, nicotinamide adenine dinucleotide phosphate; NO, nitric oxide; RNS, reactive nitrogen species; ROS, reactive oxygen species; $\mathrm{O}_{2}^{-}$: superoxide anion; $\mathrm{OH}^{-}$, hydroxyl radical; $\mathrm{ONOO}^{-}$, peroxynitrite). 


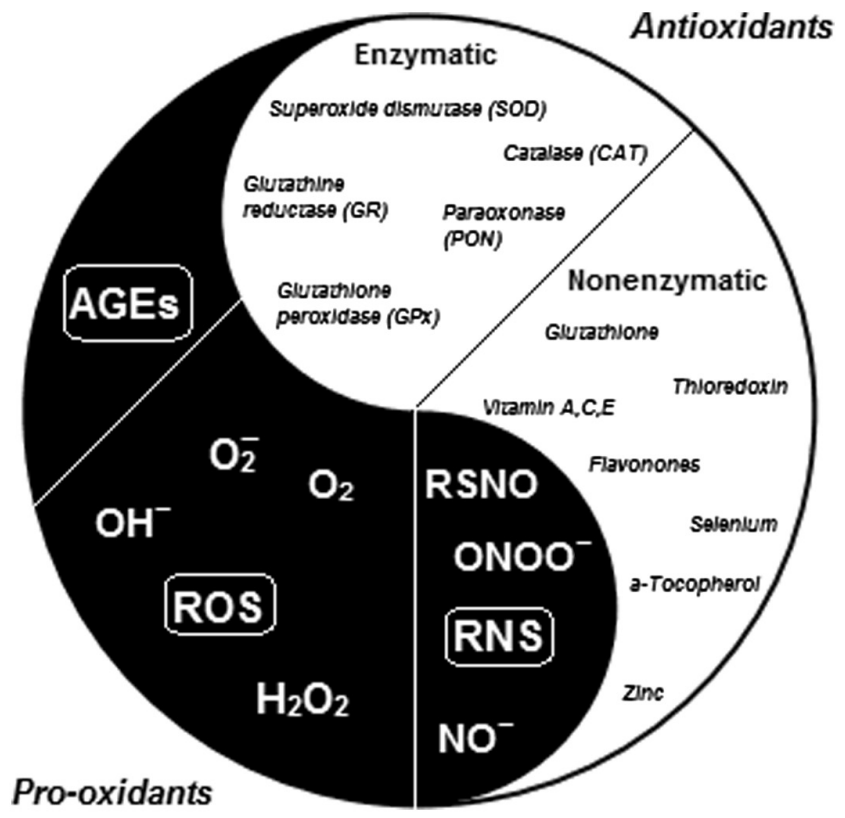

Figure 2

Pro-oxidants and antioxidants represent the 'yin and yang' of human body, as these opposite forces are actually complementary, interconnected and give rise to each other (AGEs, advanced glycation end products; $\mathrm{H}_{2} \mathrm{O}_{2}$, hydrogen peroxide; $\mathrm{NO}^{-}$, nitroxyl; $\mathrm{O}_{2}^{-}$, superoxide anion; $\mathrm{OH}^{-}$, hydroxyl radical; $\mathrm{ONOO}^{-}$, peroxynitrite; RNS, reactive nitrogen species; ROS, reactive oxygen species; RSNO, S-nitrosothiol).

ROS initiate multiple molecular pathways $(12,25,26)$. This active implication of ROS in multiple molecular pathways has led scientific society to investigate the role of oxidative stress not only in the pathophysiology of a variety of diseases $(5,27,28,29,30,31)$ but also in normal physiological functions of human body, such as nutrition. Since the establishment of the bidirectional association between caloric intake and low-grade inflammation (32), a crucial query emerged whether macronutrients themselves can be inflammatory and pro-oxidant stimuli for the human body that can postprandially trigger oxidative stress and alter body's homeostasis (33).

\section{Nutrition is a major modulator of oxidative stress}

\section{Nutrition triggers oxidative stress early in life}

Since the establishment of the 'Developmental origins of health and diseases' hypothesis, which postulates that early life development is critically sensitive to environmental stimuli, there is an increasing share of literature focusing on how environmental factors acting during early human development can affect the risk for health and disease.

Among environmental factors, nutrition as a potent promoter of these intrauterine epigenetic modifications has been extensively studied (34). Specifically, undernutrition in utero and low birth weight, combined with early catch-up growth during infancy has been linked to increased risk for obesity, insulin resistance, cardiovascular disease and reproductive dysregulation in adulthood $(35,36,37)$. Likewise, offspring raised in the context of a prenatally rich nutritional environment are at an increased risk for cardiometabolic disorders and compromised fertility later in life $(38,39)$.

Oxidative stress has been proposed as a potential mediator of nutrition-induced epigenetic changes through various experimental models (40). Maternal malnutrition, obesity or obesogenic maternal diet during gestation, but not during postweaning period (41), was associated with increased oxidative stress markers and impaired antioxidant capacity in the offspring, making them vulnerable to diabetogenic effects $(42,43)$. Simultaneously, antioxidant supplementation was accompanied by a significant attenuation of adiposity in their offspring (44).

Currently, the majority of evidence regarding the domain of developmental programming originates from experimental models, and there is a long way until definitive conclusions be established. However, nutrition during the critical periods of prenatal and perinatal development can induce epigenetic changes, via different pathways, including generation of oxidative stress, an evolving risk factor for metabolic as well as reproductive disorders in adulthood.

\section{Nutrition and oxidative stress at the cellular level}

The initial observation by Mohanty et al. demonstrating that a macronutrient induces inflammation and ROS generation by polymorphonuclear (PMN) and mononuclear (MNC) leukocytes was after glucose intake by normal subjects (45). Analogous findings for lipid and protein intake were also published. Acute ingestion of saturated fat (cream) led to an increase in ROS generation by leukocytes, similar in magnitude to that of glucose ingestion but more prolonged and persistent, whereas protein (cysein) intake also increased oxidative ROS formation but to a much lesser extent in comparison with glucose and lipids (46). Furthermore, evaluating a real mixed meal in healthy subjects, acute 
inflammatory changes were detected, with a decrease in IкB $\alpha$ and an increase in NF-кB binding, plasma CRP and the expression of inhibitory proteins IKK $\alpha$ and IKK $\beta$, and p47 $7^{\text {phox }}$ subunit (47).

Therefore, a new term - dietary or nutritional or postprandial oxidative stress - has been introduced to describe the postprandial state of imbalance between the pro-oxidant load and the antioxidant defense as a consequence of excess oxidative load or of inadequate supply of antioxidant nutrients (8). Postprandially, ROS formation and generation, originating from leukocytes and mitochondria, can be modulated by several coexisting factors (Fig. 3).

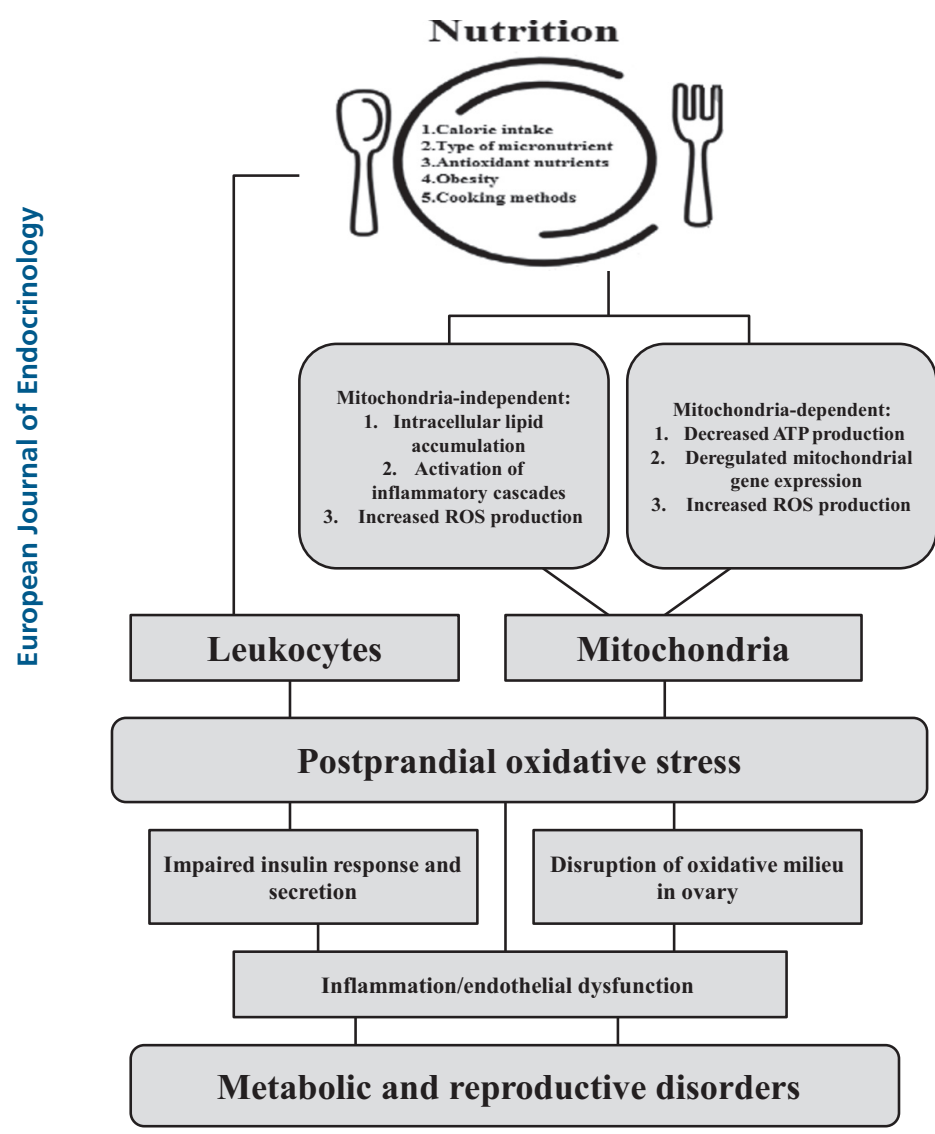

Figure 3

Food ingestion induces oxidative stress, the magnitude of which is modulated via different co-existing factors: amount of calorie intake, type of micronutrients, antioxidant nutrient consumption and cooking methods. Postprandial oxidative stress originates from two major sources: leukocytes and mitochondria. Incessant propagation of this postprandial oxidative state has been linked with metabolic and reproductive disorders.
The amount of caloric intake is a decisive factor affecting the intensity of the postprandial oxidative stress. Excessive amount of high-calorie food results in abnormal surges in blood glucose, triglycerides and free fatty acids (FFA) in blood circulation. These ample concentrations of glucose and FFA outpace the total capacity of mitochondria for oxidative phosphorylation, eventually leading to increased transfer of single electrons to molecular oxygen. As a result, more and more superoxide anions enter the circulation $(10,48,49)$. Apart from mitochondria, ROS generation by leukocytes is also affected by the caloric amount, as indicated by studies in which caloric restriction led to a respectable decrease in ROS generation by leukocytes, lipid peroxidation and protein carbonylation $(50,51,52)$.

Furthermore, the type of micronutrients consumed is also catalytic in the amplitude of postprandial oxidative stress. As mentioned above, carbohydrate and lipid consumption evokes equal oxidative responses by leukocytes, except for the fact that the latter evokes a more prolonged one. Regarding lipids, the type of fat consumed may have a role in the immediate postprandial inflammation, as saturated fats (SFA) have been closely linked to CVD, whereas $\mathrm{n}-3$ polyunsaturated fats (PUFA) are known to exert an anti-inflammatory effect $(53,54)$. However, scientific data are contradictory and have failed to prove clear beneficial effect of the consumption of PUFA-rich meals on postprandial plasma inflammatory cytokines or a detrimental effect of SFA in an acute feeding scenario $(55,56)$. Simultaneously, regarding carbohydrates, differences in postprandial oxidative stress were reported in terms of glycemic index, as consumption of high glycemic index carbohydrates by healthy subjects resulted in a more avid activation of MNCs and increased concentration of NF-кB (57).

Consumption of antioxidant and anti-inflammatory nutrients can also influence the oxidative milieu in the postprandial state. For example, orange juice intake when combined with a high-fat, high-carbohydrate meal was shown to prevent the meal-induced oxidative and inflammatory stress in normal subjects, with a total inhibition of ROS generation and a decrease in proinflammatory gene expression (58). In a similar setting, red wine, which is established to have a protective effect against atherosclerosis and CVD, was also shown to prevent meal-induced oxidative stress and mitigate the postprandial increase in LDL susceptibility to oxidation $(59,60,61)$.

Lifestyle characteristics of an individual, such as presence of obesity or physical inactivity, can also affect ROS generation in the postprandial state. Therefore, 
as depicted in a study by Bloomer et al., obese subjects experience an exaggerated and more persistent oxidative stress in response to a high-fat meal in comparison with non-obese healthy individuals (62). Regarding exercise, contradictory data prevail in the literature concerning its effect in postprandial oxidative stress. Although exercise is considered as a powerful tool of upregulating endogenous antioxidant defenses, various researches have failed to display a beneficial effect of training status in the postprandial oxidative stress $(63,64,65)$.

Finally, cooking methods can also have an aggravating impact on oxidative metabolism postprandially. Foods, high in protein and fat, cooked shortly under high temperature lead to formation of dietary AGEs (12). Uribarri et al. showed that a single oral challenge by AGEs (coke) resulted postprandially in acute endothelial dysfunction, as depicted by a significant decrease in flow-mediated dilatation both in healthy and in diabetic subjects (66). Dietary AGEs seem to have a negative impact on reproductive disturbed women, as well. In a study by our group in women with PCOS, it was shown that lowAGE diet in conjunction with 6-month administration of a lipase inhibitor (orlistat) led to a respectable improvement of their hormonal profile, independent of BMI changes (67).

Taken all the above into account, there is a large body of evidence indicating that nutrition induces major inflammatory and oxidative derangements in the postprandialstate. Indeed, postprandial hyperglycemia and hyperlipidemia, or so-called postprandial dysmetabolism, are slowly gaining important attention as major risk factors in various diseases. Incessant accumulation of all these derangements during the continuous postprandial state that characterizes modern lifestyle may contribute to the pathophysiology of metabolic and reproductive disorders in women as well.

\section{Nutrition and oxidative stress at the metabolic tissues level}

Nutrient ingestion triggers a major inflammatory and oxidative response at the cellular level altering the metabolic status of the tissues. Postprandial oxidative stress, after carbohydrate, lipid and protein intake, orchestrates a domino of metabolic changes in different tissues including adipose tissue, skeletal muscle, liver and pancreatic $\beta$-cells. These active but metabolically disturbed tissues interacting with nutrients will further aggravate oxidative stress and ultimately initiate an endless vicious cycle (Fig. 4).

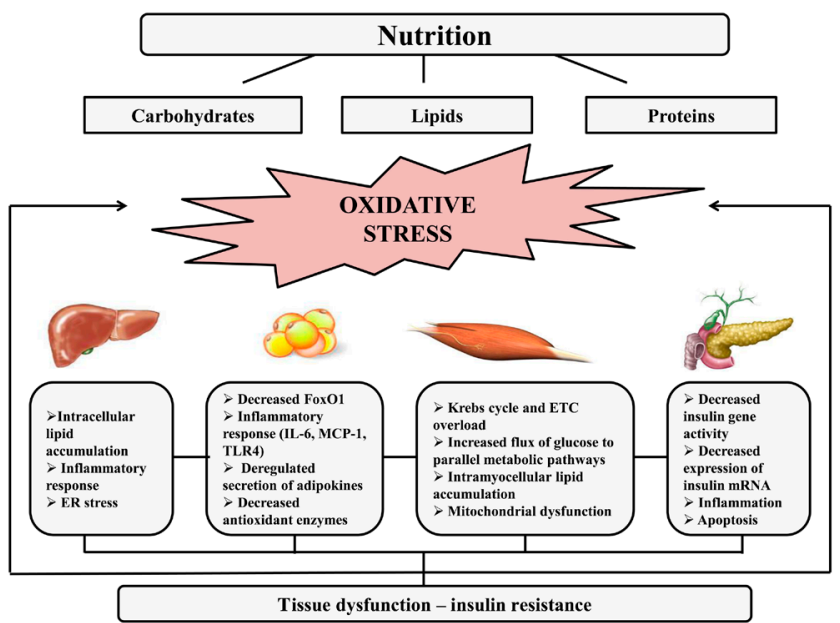

Figure 4

Nutrition as mediator of oxidative stress at the metabolic tissues level (ER: endoplasmic reticulum, FoxO1: Forkhead box protein 01, IL- 6: Interleukin 6, MCP-1: Monocyte chemoattractant protein-1, TLR4: Toll-like receptor 4, ETC: electron transport chain).

\section{Adipose tissue}

Adipose tissue is as an active endocrine organ with multiple metabolic and hormonal actions with a central role in the insulin-mediated glucose uptake, contributing to the metabolic balance of the human body (68).

Oxidative metabolism and ROS production are major players in adipose tissue function (69). There are different sources of intracellular ROS in adipocytes. First, although adipocytes are not considered pure energy-producing cells, ROS may derive from mitochondria and ETC substrate overload (70). In addition, various enzymes can promote ROS production in adipocytes, such as NADPH oxidase. NADPH oxidase 4 (NOX4) is the major isoform of the enzyme expressed in adipocytes and is increased in fat cells exposed to excess nutrient derivatives, such as glucose or palmitate (71). Silencing of NOX4 in 3T3-L1 adipocytes inhibits palmitate- and glucosestimulated ROS generation underlying the importance of non-mitochondrial sources of ROS in adipocytes (72). Additionally, NOS appears to be a significant contributor to ROS generation. Endothelial NOS (eNOS) and inducible NOS (iNOS) are abundant in adipocytes and their expression was found to be higher in the white adipose tissue of obese patients compared with lean controls, suggesting that obesity is accompanied by an altered oxidative status that may possibly have an unfavorable impact on nutrient utilization postprandially (73). 
ROS in adipose tissue seem to have a potential physiological role in its metabolic function. Early reports have highlighted that insulin may elicit $\mathrm{H}_{2} \mathrm{O}_{2}$ production in adipocytes (74). This transient $\mathrm{H}_{2} \mathrm{O}_{2}$ production amplifies insulin-signaling cascade, as it enhances translocation of GLUT transporters and glucose uptake, additionally promotes lipid synthesis and inhibits lipolysis $(75,76)$.

Following consumption of a meal, an inflammatory response takes place in the adipose tissue (77). This was first shown in a rat model by Magne et al., where rats fed with high-fat meal displayed an acute postprandial activation of inflammatory signaling in visceral adipose tissue (78). Similarly, in humans as shown by Travers et al., $6 \mathrm{~h}$ after the consumption of a mixed meal by three different groups of normal-weight, overweight and obese subjects, a similar increase in IL- 6 and MCP- 1 was detected within adipose tissue, independent of the degree of adiposity (79). Furthermore, whether the specific quality and quantity of dietary fat alters postprandial inflammatory response in adipose tissue was addressed by different scientific groups, but data remain contradictory. On one hand, the LIPGENE study of 75 subjects with metabolic syndrome demonstrated that long-term consumption of a diet high in monounsaturated fat led to attenuated postprandial inflammatory response in adipose tissue compared with a saturated fat diet (80), whereas a study by Meneses et al. showed that individuals with metabolic syndrome exhibit an exacerbated postprandial adipose tissue inflammation, independent of the quality and the quantity of fat consumed (81). Apart from the direct activation of inflammatory pathways by nutrient ingestion, a high-fat diet may induce local inflammation in adipose tissue through the release of excessive FFAs. The effects of FFAs on inflammatory pathways are mediated via the Toll-like receptor (TLR-4), which further promotes macrophage accumulation in the adipose tissue and secretion of various cytokines (82).

Finally, oxidative stress can also be detected postprandially in the adipose tissue. In cultured adipocytes, elevated FFA resulted in increased oxidative stress, via NADPH oxidase activation, and oxidative stress led to a dysregulated secretion of adipokines, as shown by Furokawa et al., What's more, in the same study, increased ROS production accompanied by augmented expression of NADPH oxidase and decreased expression of antioxidative enzymes was observed in the adipose tissue of obese mice (83). Therefore, the nutrition-induced oxidative stress could possibly lead to an adverse local redox status that could interfere in the role of free radicals in adipose tissue (84).

\section{Skeletal muscle}

Skeletal muscle can be characterized as a traffic controller of the metabolic circulation. It accounts for about $80 \%$ of postprandial insulin-stimulated glucose disposal and represents a cardinal source of energy production (85). As a pure energy-producing organ, skeletal muscle is full of mitochondria that exert a regulatory role in energy homeostasis.

After nutrient intake, insulin promotes glucose uptake in skeletal muscle via GLUT4 transporters (86). This is a critical step in the body's metabolic pathways, as fuel utilization should be adjusted to fuel availability. The capacity of skeletal muscle to switch from predominantly lipid oxidation and high rates of fatty acid uptaker during fasting conditions to the suppression of lipid oxidation and increased glucose uptake, oxidation and storage under insulin-stimulated conditions is known as metabolic flexibility. Inability to switch from lipid to carbohydrate use ('metabolic inflexibility') was observed in obese patients and is associated with intramyocellular lipid accumulation and insulin resistance (87). Various factors determine the metabolic flexibility of an organism, including nutrient availability, plasma FFA levels, the availability of adipose tissue for lipid storage and the status of physical activity (88). Another factor that may be implicated in metabolic flexibility is mitochondrial oxidative capacity. Although literature data are contradictory, it was proposed that muscle mitochondrial abnormalities influence metabolic flexibility to lipid and induce insulin resistance (88).

When calorie intake exceeds energy expenditure, as a consequence of a high-fat meal, or overfeeding, ample concentrations of energy substrates, such as glucose and FFAs, accumulate intracellularly in skeletal muscle. Increased entry of glucose results in augmented glycolytic flux and glucose oxidation, which overwhelms Krebs cycle and ETC capacity, ultimately leading to increased superoxide formation and oxidative stress (48). This excess ROS promotes the inhibition of the redoxsensitive glycolytic enzyme glyceraldehyde 3-phosphate dehydrogenase (GADPH) (89). The result of GADPH inhibition is the augmented flux of glucose metabolites through multiple metabolic pathways, including polyol pathway, AGEs formation, hexosamine biosynthesis pathway, increasing DAG synthesis via PKC activation leading to further exacerbation of oxidative stress and insulin-signaling interference (90).

Simultaneously, increased plasma FFA levels also disrupt skeletal muscle insulin signaling and promote 
insulin resistance (91). Excess fat intake in conjunction with limited adipose tissue ability for fat uptake and storage leads to ectopic fat accumulation in skeletal muscle, mainly as long-chain fatty acyl-CoA, diacylglycerol (DAG), triacylglycerol (TAG) and ceramides (92). These lipid metabolites are active signaling molecules, which in turn impair signaling of insulin-stimulated intracellular pathways $(93,94,95)$. Furthermore, FFAs directly activate inflammatory pathways, saturated fatty acids activate toll-like receptor (TLR-4) in skeletal muscle promoting c-Jun NH(2)-terminal kinase (JNK) and Ikb kinase (IKK) complex activation, which results in degradation of the inhibitor of $\kappa \mathrm{B}(\mathrm{I} \kappa \mathrm{Ba})$ and nuclear factor- $\kappa \mathrm{B}(\mathrm{NF \kappa B})$ activation, which in turn inhibit insulin receptor tyrosine phosphorylation (96). Finally, lipotoxicity is also associated with endoplasmic reticulum (ER) stress. During ER stress, misfolded proteins activate the 'unfolded protein response' (UPR), responsible for ER biogenesis, protein folding and degradation of aberrantly packaged proteins. If UPR is prolonged, the persistent oxidative protein folding machinery causes ROS production, with subsequent systemic release of FFAs and inflammatory mediators $(97,98)$.

Dietary habits can also affect physiological metabolic processes in skeletal muscle through direct alterations on mitochondrial biology and function (99). In normal healthy volunteers' mitochondria isolated from skeletal muscle biopsies, fatty acid metabolite palmitoylcarnitine itself suppresses mitochondrial ATP production (100). In another study, volunteers fed an isoenergetic highfat diet for 3 days showed downregulation of genes encoding for the mitochondrial biogenesis regulators PGC- $1 \alpha$ and $-1 \beta$ and for genes encoding mitochondrial oxidative phosphorylation enzymes (101). Overall, overfeeding and increased dietary fat seems to promote mitochondrial dysfunction, with decreased ATP synthesis, impaired mitochondrial gene expression and increased ROS formation. As a result, a vicious cycle is initiated as these mitochondrial abnormalities further exacerbate the metabolic dysfunction of skeletal muscle (Fig. 5).

\section{Liver}

In a similar setting with skeletal muscle, overfeeding or dietary fat intake lead to increased FFA liver supply and intracellular lipid accumulation that have a detrimental effect in liver metabolism. Increased malonyl CoA levels in the liver promote de novo fatty acid synthesis and inhibit carnitine palmitoyltransferase-1 (CPT-1) activity. As a result, fatty acids cannot be oxidized in mitochondria and are diverted to other biosynthetic pathways, leading to formation of TAG, DAG and ceramides (102). In a rat model by Samuel et al., only 3-day high-fat feeding led to a three-fold increase of liver lipid accumulation without any significant increase in visceral or skeletal muscle fat content, suggesting that hepatic insulin resistance may precede systemic insulin resistance (103). As we mentioned above, these lipids initiate various inflammatory cascades that deregulate insulin signaling, including PKC and JNK pathways. In addition, in an experimental model by Soardo et al., FFA-exposed cultured hepatocytes displayed increased levels of oxidative and prothrombotic markers, such as NO, MDA and PAI-1 (104). Simultaneously, overfeeding and massive substrate supply to liver exposes ER to a heavy anabolic burden that consequently promotes protein misfolding and ER stress, which can promote ROS production and inflammatory signaling activation if persistently activated (102). Finally, intrahepatocellular lipid accumulation results in impaired insulinmediated suppression of hepatic glucose production and dyslipidemia characterized by elevated hepatic VLDL triglyceride secretion combined with elevated HDL-cholesterol clearance (105).

\section{Pancreatic $\beta$-cells}

Oxidative stress can significantly compromise $\beta$-cell function, as pancreatic $\beta$-cells are innately more sensitive to oxidative stress. In an experiment by Maechier et al., $\beta$-cells exposed to hydrogen peroxide activated the production of p21 cyclin-dependent kinase inhibitor and decreased insulin mRNA, ATP and calcium flux reductions in mitochondria and cytosol (106). Furthermore, as shown by Tiedge et al., $\beta$-cells are lower in antioxidant enzyme levels (SOD, catalase and glutathione peroxidase) and more sensitive to ROS adverse actions (107). Therefore, oxidative stress, induced by elevated glucose and FFA levels, chronic inflammation and insulin resistance through the above mentioned mechanisms, acts directly in pancreatic cells and alters insulin secretion (6).

Chronic elevation of plasma glucose and FFA levels in diabetic patients has detrimental effects in pancreatic cell function (108). In cultured cells of islets or HIT cells, exposure to high concentrations of glucose and FFA levels led to a decrease in insulin gene activity and insulin mRNA and impairment of insulin signaling of 
Nutrition as a mediator of oxidative stress in metabolic disorders in women

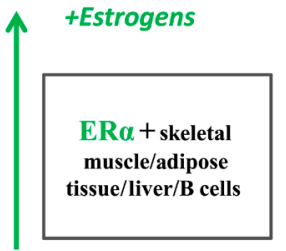

\pm Androgens

- Estrogens

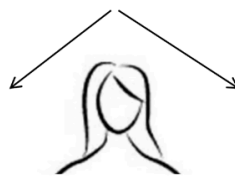

Nutrition

Skeletal
muscle/adipose tissue/liver/B cells

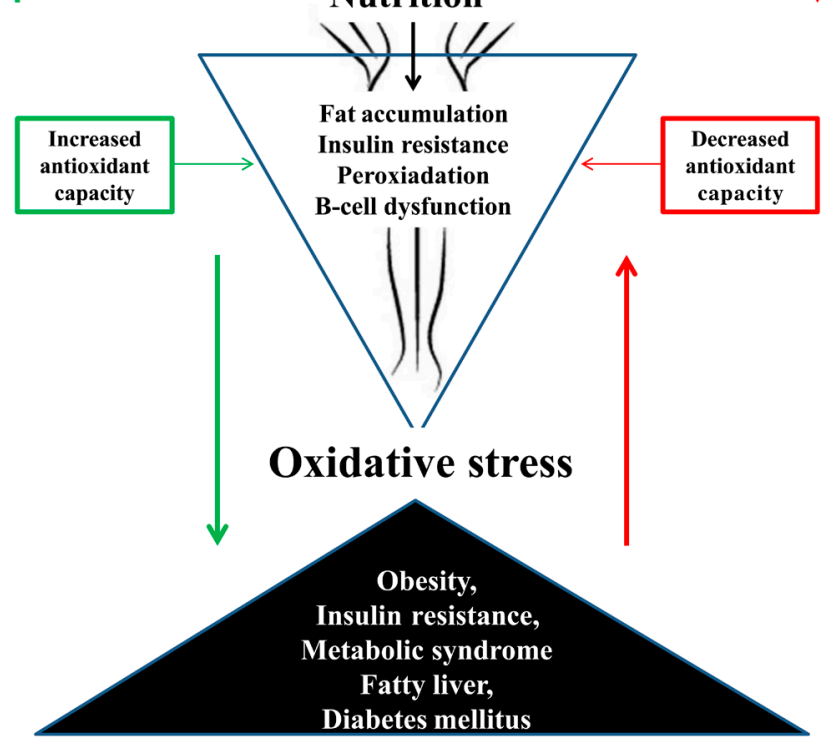

Figure 5

Nutrition as a mediator of oxidative stress in metabolic disorders in women. +ER $\alpha$ : presence of Estrogen receptors- $\alpha$ ); green arrow up: increased estrogenic activity, green square: increased antioxidant capacity through ER $\alpha$; Green arrow down: decreased oxidative stress leading to decreased fat accumulation, insulin resistance, peroxidation, B-cell dysfunction and metabolic disorders; red arrow down: decreased estrogens; square in red: decreased antioxidant capacity leading to increased fat accumulation and subsequently to increased metabolic disorders (red arrow up).

the glucose-stimulated insulin secretion (109). Oxidative stress and aberrant free radical generation can be one of the underlying mechanisms of these derangements. In addition, hyperglycemia by itself can trigger increased intracellular mitochondrial ROS formation in pancreatic $\beta$-cells, promoting a local oxidative microenvironment, which in turn activates multiple metabolic pathways that further exacerbate oxidative stress (110), including chronic low-grade inflammation and AGE production, which further deteriorate $\beta$-cell function (108).

\section{Nutrition as a mediator of oxidative stress in female metabolic and reproductive disorders}

\section{Nutrition as a mediator of oxidative stress in metabolic disorders in women}

Nutrition and calorie intake initiates a plethora of intracellular events in the major metabolic organs. Chronic hypernutrition, high-fat, high-carbohydrate meals, as well as dietary saturated fatty acids and glycotoxins stimulate multiple intracellular pathways and propagate oxidative stress. The nutrition-induced oxidative stress is emerging as one of the principal parameters that give rise to multiple metabolic disorders in women, including obesity, insulin resistance, metabolic syndrome and diabetes mellitus (Fig. 5).

In the pathogenesis of metabolic disorders and mediators of oxidative stress in women, the role of sex hormones and their imbalance has been clearly demonstrated by their impact on insulin signaling and glucose homeostasis (111).

Estrogens and their metabolites have been linked to oxidative stress. Beyond their pure reproductive effects, they are important regulators of body's metabolic function (112). Their receptors are present not only in reproductive tissues, but also in insulinsensitive organs, including skeletal muscle, liver and pancreatic $\beta$-cells, playing a modulatory role in insulinglucose homeostasis (113). Analytically, in skeletal muscle, estradiol (E2) receptor $\alpha(E R \alpha)$ has a positive effect in insulin signaling and GLUT4 expression (114). In skeletal muscle of ovariectomized mice, lipid metabolism was downregulated, inducing intracellular fat accumulation and activation of stress kinases (115). In addition, liver-specific ER $\alpha$-knockout mice fed with a high-fat diet displayed decreased insulin sensitivity, as well as failure to suppress liver glucose production (116). Estrogen receptors are also present in pancreatic $\beta$-cells and enhance lipid homeostasis, insulin biosynthesis and secretion and enhancing islet survival by protecting $\beta$-cell from oxidative stress and apoptosis (117).

Apart from the direct actions of estrogens on insulinsensitive tissues, E2 can regulate metabolism and energy expenditure indirectly via mitochondrial function and oxidative stress (118). Specifically, E2 binding to nuclear and mitochondrial receptors promotes ATP production and mitochondrial biogenesis, alters mitochondrial ROS formation, activates PCG1a and induces an antioxidant response $(119,120,121)$. Consequently, E2 
is highlighted as a natural, innate antioxidant agent of human body.

Regarding androgens, their metabolic role in females remains unclear. The majority of available data originate from women with polycystic ovary syndrome (PCOS), where hyperandrorgenemia is present. In women with PCOS, it was shown that androgen excess per se can impair insulin action and promote insulin resistance $(122,123,124)$. In addition, in a mouse model by Liu et al., female mice with androgen excess experienced systemic oxidative stress and were subsequently predisposed to pancreatic $\beta$-cell failure and diabetes mellitus (125). However, in a more recent experimental model, female androgen receptorknockout mice displayed increased body weight and body fat, decreased insulin sensitivity and marked dyslipidemia after 8-week high-fat diet, highlighting that not only androgen receptors may exert a protective effect in metabolic control but also how important is the role of balance between no androgens and excess of androgens (126).

During reproductive age, hormonal status and E2 abundance seem to favorably influence metabolism and oxidative balance. This is nicely depicted in experiments focusing on gender-dependent differences in nutritioninduced metabolic and oxidative derangements. First, in comparison to healthy young men, premenopausal women display significantly lower levels of oxidative stress (127). Analogous findings were reported postprandially, as women experienced lower oxidative stress than men, with regard to MDA and $\mathrm{H}_{2} \mathrm{O}_{2}$ levels, after ingestion of a lipid load in the form of heavy whipping cream (128). Furthermore, in an experimental model by Nickelson et al., high-fat diet was administered to weight-matched obese male and female mice. Females displayed greater adiposity and enlarged adipocyte size compared with weight-matched male mice. However, they remained more glucose tolerant, due to increased expression of adiponectin and reductions in immune cell infiltration and oxidative stress in adipose tissue (129). In a similar mouse model, males had a higher propensity to developing liver steatosis and insulin resistance after consumption of high-fat diet (130). Taken all the above into account, the metabolic and antioxidant properties of estrogens clearly protect premenopausal women from developing metabolic derangements and can be established as an important confounding factor in drawing definite conclusions about the role of nutrition-related oxidative stress in metabolic dysfunction.

Entering menopause, women experience a severe change in their reproductive potential, directly originating from estrogen-androgen imbalance with major defect of estrogen deficiency (131). Ovarian senescence affects many tissues and produces a variety of symptoms and signs. Loss of their main circulating estrogen, E2 leads to an abrupt reduction in metabolic rate, shift to increased central adiposity, dyslipidemia, progression of insulin resistance and metabolic syndrome, as well as adverse cardiovascular events (132).

In addition, the marked reduction in estrogen has been shown to increase levels of oxidative stress in the body, mainly through a decrease in antioxidant defenses (133). Women experience increased oxidative stress even during perimenopausal period, manifested by reduced PON1 A activity and elevated lipoperoxidation, DNA repair ability and total antioxidant status (134). Simultaneously, hormone replacement therapy is able to prevent and counteract such modifications by acting as regulators of key antioxidant gene expression $(135,136)$. Consequently, this pro-oxidant state that characterizes postmenopausal women potentiates the metabolic and endothelial dysfunction that characterizes postmenopausal women $(132,137)$.

The unique role of estrogen deficiency in metabolic and oxidative dysfunction during menopause was extensively evaluated in animal models, where artificial menopause and estrogen replacement were used to mimic hormonal background. The potent contribution of nutrition to this metabolic imbalance was also evaluated. In a study by Busserolles et al., ovariectomized female rats fed with highsucrose diet displayed higher susceptibility to peroxidation, in comparison with intact females or ovariectomized females supplemented with estradiol (138). Furthermore, in another experimental model, ovariectomized rats fed with high-fat diet showed a marked reduction of whole blood antioxidants with a concomitant elevation of oxidant markers, as well as glucose intolerance and insulin resistance. Administration of soy isoflavones significantly improved these derangements (139). Analogously, Camporez et al. demonstrated that 4-week high-fat diet in ovariectomized mice led to increased body weight and fat mass, reduced whole-body energy expenditure, impaired glucose tolerance and whole-body insulin resistance in comparison to ovariectomized mice receiving hormone replacement therapy (140). Large clinical studies have also underlined the protective effect of estrogen against insulin resistance and metabolic dysfunction. In a population-based prospective cohort study, diabetes risk was reduced by $62 \%$ in women with current hormone replacement therapy (HRT) use compared with control 
individuals (141). HRT also improved glucose control in women with preexisting diabetes and increased insulin sensitivity (142).

Concluding, calorie intake and its subsequent oxidative stress can significantly contribute to the development of various metabolic disorders in women. However, the hormonal background, with or without estrogens/with or without androgen excess, of every woman is a decisive denominator in this co-interaction, as hormonal fluctuations can uniquely determine her metabolic state.

\section{Nutrition as a mediator of oxidative stress in female reproductive disorders}

Oxidative metabolism is a critical intraovarian regulator of folliculogenesis. Free radicals and antioxidants seem to play a complex and multifunctional role in the ovarian environment during different stages of physiological oocyte maturation, as seen in Fig. 6. For example, on one hand, resumption of meiosis I of a primary follicle is induced by an increase in ROS and inhibited by antioxidants, suggesting that controlled ROS production by the preovulatory follicle is an important promoter of the ovulatory evolution, whereas on the other hand, ROS adversely affect meiosis II progression, leading to diminished gonadotropin and antisteroidogenic actions, DNA damage and inhibited protein ATP production (143). Apart from folliculogenesis, oxidative metabolism is also implicated in other functions of female reproductive system. In ovarian steroidogenesis, it has been shown that ovary overexposed to $\mathrm{H}_{2} \mathrm{O}_{2}$ led to impaired cholesterol utilization and protein synthesis, mainly through altered production of steroidogenic acute regulatory protein (StAR) (143). In addition, exposure to oxidative stress before fertilization leads to disrupted meiotic spindle and increased risk for abnormal zygote formation, especially when antioxidant defenses are insufficient (144). Finally, NO seem to carry a critical, regulatory role during embryonic development and implantation (145). Although its function is not established, NO seems to contribute as an anti-platelet agent, as well as a regulator of cyclic GMP, which mediates estrogen-stimulated uterine secretory response at the implantation site (146). Overall, oxidative equilibrium in the ovarian microenvironment and preservation of a delicate oxidative balance are crucial in order to secure normal ovum function and development.

Consequently, a plethora of studies have been conducted so far in order to explore the putative role of oxidative stress in fertility. The majority of them involve women undergoing assisted reproductive techniques
(ART), where various systemic and follicular fluid markers of oxidative stress were correlated with fertilization and pregnancy outcomes. Specifically, increased levels of MDA, ROS, NO and lipid peroxidation (LPO) in follicular fluid of women undergoing ART were associated with lower ovarian response, poorer embryo quality, decreased fertilization and pregnancy rates $(147,148,149)$. On the other hand, follicular fluid total antioxidant capacity (TAC) of patients undergoing IVF was positively associated with success rates $(150,151)$, whereas enhanced blood plasma antioxidant status was shown to be beneficial in achieving pregnancy in these women (152).

The role of nutrition and its impact on inducing local oxidative stress in the ovarian milieu has also been investigated, but to a much lesser extent. In an experimental model by Valckx et al., early secondary murine follicles were cultured in vitro in the presence of FFAs until the antral stage and it was shown that elevated FFA concentrations can potentially impair fertility, by altering follicular physiology and reducing oocyte developmental competence (153). Analogously, an observational study of 236 women undergoing assisted reproduction program revealed that fatrich diet can induce oxidative stress in oocyte environment and negatively influence embryonic development (154). However, Kazemi et al. failed to prove a potential relationship between total calorie intake, BMI and physical inactivity with oxidative biomarkers in follicular fluid (155).

Finally, increased dietary AGE consumption contributes to increased AGE deposition in ovarian tissue, promoting significant perturbations in ovarian microenvironment and ovulatory dysfunction (156). Recently, different research groups have investigated the potential role of AGE-RAGE system in female infertility (157). Jinno et al., in a retrospective analysis of women undergoing IVF, have documented that serum and follicular fluid AGE levels negatively correlated with follicular growth, fertilization rates and embryonic development. What's more, lower follicular fluid AGE levels were the most significant predictors of pregnancy outcomes (158). In another study of women undergoing IVF, follicular fluid levels of soluble form of RAGE (sRAGE) significantly correlated with conception rates (159). Finally, sRAGE seems to be positively correlated with AMH, a well-known marker of ovarian reserve (160). Overall, intraovarian AGE accumulation can be a decisive parameter in the initiation of ovarian dysfunction, which can potentially lead to infertility.

Concluding, oxidative metabolism has a unique role in female reproductive physiology (Fig. 6). There is a delicate, marginal threshold distinguishing beneficial and 
Nutritional oxidative stress: an important intraovarian regulator in female reproductive disorders

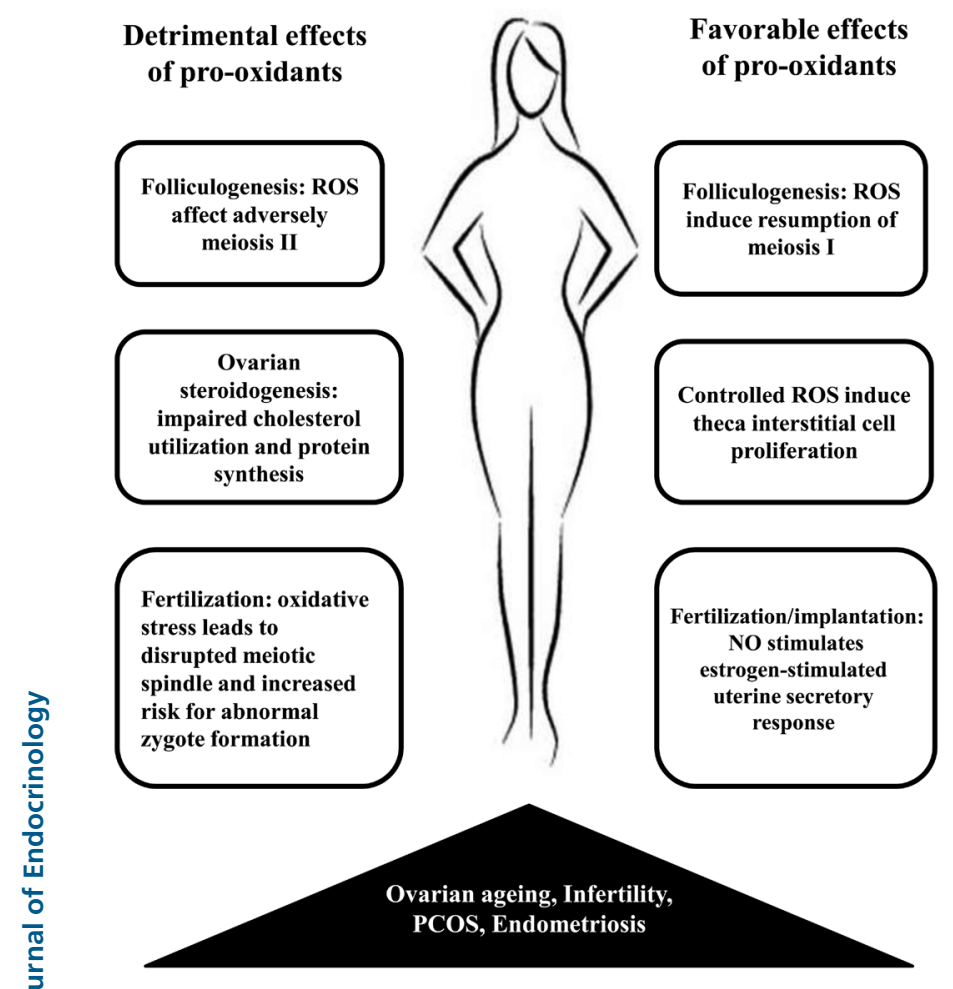

Figure 6

Nutritional oxidative stress: an important intraovarian regulator in female reproductive disorders. Dysequilibrium between pro-oxidants affects intraovarian environment and alters female reproduction. Nutritional oxidative stress can augment detrimental effects of pro-oxidants and mediate the manifestation of various reproductive disorders. (ROS: Reactive oxygen species, NO: nitric oxide, PCOS: polycystic ovary syndrome).

harmful effects of oxidative stress and tightly controlled pro-oxidant:antioxidant ratio is mandatory to secure normal ovarian function. Therefore, oxidative stress could be a potent, underlying mechanism of various reproductive abnormalities (5). However, data establishing solid conclusions about the role of nutrition-promoted oxidative stress in female reproductive dysfunction, as a therapeutic target, are limited.

\section{Ovarian aging}

Ovarian functional decline with aging has been so far extensively characterized in terms of gradual depletion of ovarian follicles and reduced ability to produce oocytes competent for fertilization and further development (161). Oxidative stress-induced ovarian aging originates from a continuous imbalance, derived by excessive ROS generation combined with antioxidant levels decline (162).

Analytically, serum concentrations of inflammatory cytokines and pro-oxidant biomarkers such as oxidized lipoproteins (ox-LDL), 4-hydroxynenal and MDA were found to be higher in postmenopausal women than in premenopausal women (163). In contrast, GSH and glutathione transferase, which are effective in the removal of free radicals, are reduced in oocytes with age (164). With the weakening of the antioxidant defense, aging also occurs in granulosa cells, accompanied by $\mathrm{Cu} / \mathrm{Zn}$ superoxide dismutase, Mn superoxide dismutase and catalase downregulation (165). Similarly, as shown by a mouse model by Lim et al., significant age-related increases in oxidatively damaged lipids, proteins and DNA are observed in different ovarian compartments, including granulosa cells and ovarian interstitial tissue, along with alterations of antioxidant enzyme expression (166). Finally, hormonal alterations that accompany ovarian aging, such as the marked reduction in estrogen, have been shown to increase levels of oxidative stress in the body (167).

Furthermore, AGEs may also be involved in the process of ovarian aging. A study by our group demonstrated that AGEs are present in normal ovarian tissue obtained from reproductive-aged women, whereas RAGE was highly expressed in the ovary being present in granulosa theca interna, endothelial and stromal cells (168). In addition, increased levels of pentosidine were observed in the primordial, primary and atretic follicles of premenopausal women, findings that suggest a possible correlation of AGEs with ovarian aging (169). Consequently, potential accumulation of these compounds in the ovary across life span may initiate adverse molecular intraovarian events, such as compromised efficiency of vascularization and activation of oxidative stress response through RAGE interaction, and ultimately trigger ovarian dysfunction (170). Finally, the activity and expression of glyoxalase-1 (GLO1), a powerful enzymatic system of AGE scavenging, was also found to be decreased in aged ovaries of mice (171).

Overall, experimental data regarding the role of oxidative stress in ovarian aging are only indicatory and further investigation of the network involving mitochondrial dysfunction and ROS overload in the follicle should be encouraged. The role of nutrition and the direct effects of nutrition-induced oxidative stress in the ovary have not been adequately evaluated and 
warrant more experimental and clinical models, in order to reach more definite conclusions.

\section{Unexplained infertility}

Idiopathic (unexplained) infertility is diagnosed by exclusion and is defined as the inability to conceive after 12 months of timed, unprotected intercourse where tests have been performed on both partners to rule out known causes of infertility, including but not limited to anovulation and sperm defects (5). Although its etiology remains unclear, it is believed that oxidative stress significantly contributes to its pathogenesis.

Total antioxidant status was found to be lower in peritoneal fluid of women with idiopathic infertility compared with fertile controls (172), whereas elevated levels of ROS in the peritoneal fluid of women with idiopathic infertility were also reported by Wang et al. and Polak et al. $(172,173)$. However, a study in which $\mathrm{N}$-acetyl cysteine (NAC), a potent antioxidant compound, was administrated with clomiphene citrate for ovulation induction in women with unexplained infertility failed to improve ovulation rates in comparison to women treated only with clomiphene citrate (174).

Human studies regarding the role of nutritioninduced oxidative stress in infertility are limited. The majority of them have focused on follicular fluid composition in women undergoing IVF where follicle maturation is stimulated with exogenous hormones, creating a milieu that differs from the FF of women without ovarian stimulation. Therefore, future, prospective, well-designed pregnancy studies, in which dietary interventions and biological sample examinations can take place, are mandatory in order to investigate deeper the field of diet-induced oxidative stress in female infertility.

\section{Polycystic ovary syndrome}

Polycystic ovary syndrome (PCOS) is one of the most common endocrinopathies of premenopausal women, encountered in everyday clinical practice (175). Its etiopathophysiological core remains vague; however, gonadotropin-secretory alterations, androgen excess, insulin resistance and low-grade inflammation, in conjunction with the pivotal contribution of genetic and environmental parameters, are all involved in the interplay net of the syndrome $(176,177)$. Recently, oxidative stress has also been highlighted as another potent modulator of PCOS $(178,179)$.
Various pro-oxidant biomarkers have been shown to be altered in PCOS. Specifically, in a recent meta-analysis by Murri et al., homocysteine, malondialdehyde (MDA) and asymmetric dimethylarginine (ADMA) levels were shown to be elevated in women with PCOS (180). Conversely, levels of antioxidants also seem to be affected in women suffering from PCOS, conserving the redox imbalance and perpetuating oxidative stress. Total antioxidant capacity (TAC), an aggregative index of plasma antioxidant state, which represents the ability of human body to eliminate free radicals, was found to be decreased in women with PCOS $(181,182)$, whereas various abnormalities were also detected in the concentrations of enzymatic antioxidants, such as paraoxonase-1 (PON-1) and glutathione, whose activities were shown to be decreased, and superoxide dismutase (SOD), whose activity was enhanced in women with PCOS $(180,183,184)$.

Nutrition-induced oxidative stress, through postprandial hyperglycemia, has also been studied in PCOS. Specifically, increased ROS production by monocytes in response to hyperglycemia was observed in women suffering from PCOS, independent of the presence of obesity and abdominal adiposity, via stimulating secretion of inflammatory markers (i.e., TNF-a and NF- $\mathrm{kB})$ and activation of NADPH oxidase $(185,186)$. What's more, hyperglycemia was also shown to alter the action of enzymatic antioxidants, such as glutathione peroxidase (GPx) (187), and hyperandrogenemia, which predominates in PCOS, seems to significantly contribute to increased sensitization of leukocytes to hyperglycemia and the concomitant upregulation of the expression of various inflammatory markers even in lean women with PCOS $(188,189)$. Interestingly, apart from insulin sensitivity, it was recently shown by Malin et al. that hyperglycemia-induced inflammation has an adverse impact on pancreatic $\beta$-cell function, further exacerbating glycemic dysregulation in women with PCOS $(190,191)$.

PCOS could serve as a model in which reproductive and metabolic abnormalities could be uniquely linked to oxidative stress, as oxidative stress contributes to both reproductive and metabolic dysfunctions that characterize women suffering from PCOS. Regarding metabolic signaling, PCOS is commonly accompanied by obesity, abdominal adiposity, insulin resistance and endothelial dysfunction (176). As discussed above, oxidative stress is a common denominator of all these pathophysiological processes and seems to drive analogous detrimental cellular events in women with PCOS, as well (48). Regarding reproduction, accumulating data highlight the role of oxidative stress 
in the microenvironment of the ovary in PCOS. Women with PCOS displayed increased follicular fluid levels of ROS and MDA, as well as decreased total antioxidant capacity (TAC), which were directly associated with lower rates of oocyte maturation and fertilization, poor embryo quality and decreased pregnancy rates $(146,192$, 193). In fact, in a study by Karuputhula et al., various markers of oxidative stress were assessed in different populations of infertile women who underwent IVF (194). Among the whole cohort, women with PCOS displayed the highest levels of ROS in granulosa cells and were accompanied by poorer fertilization rates (194). Finally, we should mention a recent study of a hyperandrogenism-induced murine model of polycystic ovary by Rezvanfar et al., in which various markers of oxidative stress were found to be altered both in serum and follicular fluid, derangements that also prevail in ovarian aging process. Not surprisingly, it is implied that PCOS may induce acceleration of aging process and early washup of ovarian reserve (195). However, clinical data from human studies do not seem to confirm an early menopause in women with PCOS $(196,197)$.

Equally significant are the data on AGEs, derived from studies in PCOS women. AGEs are known to be extremely inflammatory with dominant pro-oxidant capacity, produced endogenously as well as deriving mostly from diet. AGEs were shown to be distinctively elevated in women with PCOS, independent of the presence of obesity and insulin resistance, exerting unfavorable effects in both reproductive and metabolic function of these women (198). Also, AMH correlates strongly with AGE levels in PCOS women, a finding in human studies indicating the potential role of oxidative stress in the follicular maturation process (199).

AGEs have a direct impact on the ovarian cells of women with PCOS. Specifically, female high-AGE-fed rats displayed increased deposition of AGEs and RAGE in theca and granulosa cells, as well as downregulated ovarian glyoxalase-1 activity, a protective enzyme against glycation $(200,201)$. PCO ovaries displayed increased AGE deposition in theca, granulosa and endothelial ovarian cells and higher expression of RAGE as well as NF-kB p65 subunit in granulosa cells (168). Accumulating AGEs interfere with intracellular ovarian signaling pathways, specifically with insulin signaling in granulosa cells with potential interference in ovarian dysfunction in PCOS (202). Concerning metabolic dysfunction, it is well established that AGEs are closely linked to insulin resistance. In a mouse model by Cai et al., it was demonstrated that mice fed with a high-
AGE diet demonstrated insulin resistance, abdominal adiposity and eventually diabetes, in comparison with mice fed with an isocaloric AGE-free diet (203). In an analogous human model by Tantalaki et al., lower dietary AGE intake in women with PCOS resulted in a parallel decrease in serum AGE, insulin levels, HOMA-IR and oxidative stress markers, depicting a significant improvement of their metabolic profile (204).

Oxidative stress holds a respectable share in the etiology of metabolic and reproductive aberrations in PCOS, as these women display hyperandrogenemia and insulin resistance, both of which are aggravators of the oxidative status and vice versa. Although more research is mandatory in order to set solid knowledge, it becomes evident that oxidative stress, in conjunction with the rest etiological parameters, orchestrates the pathogenetic process in reproductive as well as in metabolic abnormalities in women with PCOS.

\section{Endometriosis}

Endometriosis is a benign gynecologic disorder of unknown etiology, in which endometrial tissue is present outside the uterus, most often in ovaries, abdominal viscera, urinary tract or even in lungs. Endometriosis affects $6-10 \%$ of women of reproductive age and has been associated with infertility. Various theories have been postulated regarding the pathophysiology of endometriosis, one of which is oxidative stress (5).

After bleeding and hemolysis in endometriosis, the pro-oxidant hemoglobin transfers heme and iron derivatives to endometriotic lesions or peritoneal cavity. As free heme and iron are considered generally toxic compounds, autoxidation of hemoglobin takes place, leading to excessive production of ROS that in turn activates multiple signaling pathways, cytokine release and apoptosis. Cellular oxidant property and antioxidant defenses are decisive in determining the extent of cell death (205).

A plethora of scientific studies have focused on investigating the role of nutrition-related oxidative stress in endometriosis. Data are mainly contradictory in bibliography. Although some studies failed to observe increased oxidative stress in the peritoneal fluid or circulation of patients with endometriosis, others have reported increased levels of oxidative stress markers in those with the disease (5). In a recent study by Singh et al., increased concentration of ROS, NO, LPO, iron, lead, cadmium and reduced levels of TAC, SOD, catalase, GPx, glutathione reductase (GR), vitamins A, C, E, copper, zinc 
and selenium was observed in women with endometriosis undergoing IVF (149). Analogously, the peritoneal fluid of these patients has also been found to contain high concentrations of MDA, proinflammatory cytokines (IL-6, TNF-alpha and IL-beta), angiogenic factors (IL-8 and VEGF), MCP-1 and ox-LDL (206). Furthermore, endogenous antioxidant compounds are also disrupted in women suffering from endometriosis. Specifically, lower plasma SOD concentration, lower follicular fluid vitamin $\mathrm{C}$ levels and imbalanced intrafollicular thiolredox system were detected in infertile women with endometriosis, in comparison with controls $(207,208)$. In a study by Mier-Cabrera et al., when a high-antioxidant diet was administered in women with endometriosis, peripheral oxidative stress markers, including MDA and lipid hydroperoxides, were significantly attenuated and antioxidant markers, specifically SOD and GPx, were enhanced (209). However, laboratory data were not correlated with clinical outcomes, in order to reach possible links and conclusions.

\section{Long-term effects of nutrition in oxidative homeostasis}

Nutrition-induced oxidative and inflammatory milieu in an acute setting can modify intracellular and extracellular physiological functions. When these derangements are repeated, they impose a sustained oxidative and inflammatory status, which, in turn, can predispose to a variety of diseases.

In a study by Vlassara et al., in which high-AGE diet fed for 6 weeks in diabetic patients resulted in a significant increase in serum TNF-a, CRP and VCAM-1 levels depicted the potent inflammatory actions of AGEs that can potentially lead to tissue injury (19). Simultaneously, in female high-AGE-fed mice, increased deposition of AGEs and RAGE in ovarian tissues was observed, altering the cellular milieu and downregulating glyoxalase-1, a protective enzyme against glycation, ultimately leading to ovarian dysfunction $(200,201)$.

On the other hand, restricted calorie nutritional patterns can exert the exactly opposite effect, securing oxidative balance and promoting cell longevity. For example, 6-month caloric restriction attenuated oxidative stress and decreased significantly fasting insulin levels and body core temperature (two markers of longevity) in healthy individuals (210). In addition, in a study by Ceriello et al., diabetic patients following a Mediterranean diet for 3 months, enriched in monounsaturated fatty acids or polyunsaturated fatty acids and polyphenols, displayed increased plasma antioxidant capacity and improved basal endothelial function, in comparison with controls (211).

Overall, it becomes clearly evident that nutrition acts catalytically in the maintenance of oxidative balance both in an acute and in a chronic setting. Nutritional divergences can easily violate this cellular balance, initiate detrimental pathophysiological pathways and promote the occurrence of various diseases in women.

\section{Conclusion}

Nutrition constitutes one of the major modulators of oxidative stress in human body. Nutrient intake and its accompanying postprandial oxidative stress initiate a clustering of molecular changes in the main signaling pathways of various organs, unfavorably alter the cellular milieu. Specifically in women, nutritional oxidative stress modulates and interferes directly and indirectly with the metabolic and reproductive functions, which are ultimately compromised. Nevertheless, the exact pathophysiological links are still escaping, making targeted therapeutic modalities a challenging field. Therefore, in women with metabolic and reproductive disorders, modification of nutritional habits by reduction of food quantity remains the most well-studied factor, but the quality and the timing of meals should also be taken into account as are currently considered as contributors.

\section{Declaration of interest}

The authors declare that there is no conflict of interest that could be perceived as prejudicing the impartiality of this review.

\section{Funding}

This research did not receive any specific grant from any funding agency in the public, commercial or not-for-profit sector.

\section{References}

1 Commoner B, Townsend J \& Pake GE. Free radicals in biological materials. Nature 1954174 689-691. (doi:10.1038/174689a0)

2 Halliwell B. Reactive oxygen species in living systems: source, biochemistry, and role in human disease. American Journal of Medicine 199191 14S-22S. (doi:10.1016/0002-9343(91)90279-7)

3 Turrens JF. Mitochondrial formation of reactive oxygen species. Journal of Physiology 2003552 335-344. (doi:10.1113/ jphysiol.2003.049478)

4 Dalle-Donne I, Rossi R, Colombo R, Giustarini D \& Milzani A Biomarkers of oxidative damage in human disease. Clinical Chemistry 200652 601-623. (doi:10.1373/clinchem.2005.061408)

5 Agarwal A, Aponte-Mellado A, Premkumar BJ, Shaman A \& Gupta S. The effects of oxidative stress on female reproduction: 
a review. Reproductive Biology and Endocrinology 20121049. (doi:10.1186/1477-7827-10-49)

6 Tangvarasittichai S. Oxidative stress, insulin resistance, dyslipidemia and type 2 diabetes mellitus. World Journal of Diabetes 20156 456-480. (doi:10.4239/wjd.v6.i3.456)

7 Halliwell B. Oxidative stress, nutrition and health. Experimental strategies for optimization of nutritional antioxidant intake in humans. Free Radical Research 199625 57-74. (doi:10.3109/10715769609145656)

8 Sies H, Stahl W \& Sevanian A. Nutritional, dietary and postprandial oxidative stress. Journal of Nutrition 2005135 969-972.

9 Fisher-Wellman K \& Bloomer RJ. Macronutrient specific postprandial oxidative stress: relevance to the development of insulin resistance. Current Diabetes Reviews 20095 228-238. (doi:10.2174/157339909789804369)

10 O'Keefe JH \& Bell DS. Postprandial hyperglycemia/hyperlipidemia (postprandial dysmetabolism) is a cardiovascular risk factor. American Journal of Cardiology 2007100 899-904. (doi:10.1016/ j.amjcard.2007.03.107)

11 Halliwell B \& Cross CE. Oxygen-derived species: their relation to human disease and environmental stress. Environmental Health Perspectives 1994102 (Supplement 10) 5-12. (doi:10.1289/ ehp.94102s105)

12 Droge W. Free radicals in the physiological control of cell function. Physiological Reviews 200282 47-95. (doi:10.1152/physrev.00018.2001)

13 Davies KJ. Oxidative stress: the paradox of aerobic life. Biochemical Society Symposium 199561 1-31. (doi:10.1042/bss0610001)

14 Rosselli M, Keller PJ \& Dubey RK. Role of nitric oxide in the biology, physiology and pathophysiology of reproduction. Human Reproduction Update 19984 3-24. (doi:10.1093/humupd/4.1.3)

15 Forstermann U \& Sessa WC. Nitric oxide synthases: regulation and function. European Heart Journal 201233 829-837, 837a-837d. (doi:10.1093/eurheartj/ehr304)

16 Pacher P, Beckman JS \& Liaudet L. Nitric oxide and peroxynitrite in health and disease. Physiological Reviews 200787 315-424. (doi:10.1152/physrev.00029.2006)

17 Vlassara H \& Palace MR. Diabetes and advanced glycation endproducts. Journal of Internal Medicine 2002 251 87-101. (doi:10.1046/j.1365-2796.2002.00932.x)

18 Ramasamy R, Yan SF \& Schmidt AM. Advanced glycation endproducts: from precursors to RAGE: round and round we go. Amino Acids 201242 1151-1161. (doi:10.1007/s00726-010-0773-2)

19 Vlassara H, Cai W, Crandall J, Goldberg T, Oberstein R, Dardaine V, Peppa M \& Rayfield EJ. Inflammatory mediators are induced by dietary glycotoxins, a major risk factor for diabetic angiopathy. PNAS 200299 15596-15601. (doi:10.1073/pnas.242407999)

20 Ott C, Jacobs K, Haucke E, Navarrete Santos A, Grune T \& Simm A. Role of advanced glycation end products in cellular signaling. Redox Biology 20142 411-429. (doi:10.1016/j.redox.2013.12.016)

21 Pisoschi AM \& Pop A. The role of antioxidants in the chemistry of oxidative stress: a review. European Journal of Medicinal Chemistry 201597 55-74. (doi:10.1016/j.ejmech.2015.04.040)

22 Sies H. Oxidative stress: oxidants and antioxidants. Experimental Physiology 199782 291-295. (doi:10.1113/expphysiol.1997.sp004024)

23 Valko M, Leibfritz D, Moncol J, Cronin MT, Mazur M \& Telser J. Free radicals and antioxidants in normal physiological functions and human disease. International Journal of Biochemistry and Cell Biology 200739 44-84. (doi:10.1016/j.biocel.2006.07.001)

24 Burton GJ \& Jauniaux E. Oxidative stress. Best Practice and Research Clinical Obstetrics and Gynaecology 201125 287-299. (doi:10.1016/j. bpobgyn.2010.10.016)

25 Finkel T. Reactive oxygen species and signal transduction. IUBMB Life 2001 52 3-6. (doi:10.1080/15216540252774694)

26 Allen RG \& Tresini M. Oxidative stress and gene regulation. Free Radical Biology and Medicine 200028 463-499. (doi:10.1016/ S0891-5849(99)00242-7)
27 Li H, Horke S \& Forstermann U. Vascular oxidative stress, nitric oxide and atherosclerosis. Atherosclerosis 2014237 208-219. (doi:10.1016/j.atherosclerosis.2014.09.001)

28 Reuter S, Gupta SC, Chaturvedi MM \& Aggarwal BB. Oxidative stress, inflammation, and cancer: how are they linked? Free Radical Biology and Medicine 201049 1603-1616. (doi:10.1016/ j.freeradbiomed.2010.09.006)

29 Maritim AC, Sanders RA \& Watkins JB 3rd. Diabetes, oxidative stress, and antioxidants: a review. Journal of Biochemical and Molecular Toxicology 200317 24-38. (doi:10.1002/jbt.10058)

30 Finkel T \& Holbrook NJ. Oxidants, oxidative stress and the biology of ageing. Nature $2000 \mathbf{4 0 8} 239-247$. (doi:10.1038/35041687)

31 Bhat AH, Dar KB, Anees S, Zargar MA, Masood A, Sofi MA \& Ganie SA. Oxidative stress, mitochondrial dysfunction and neurodegenerative diseases; a mechanistic insight. Biomedicine and Pharmacotherapy 2015 74 101-110. (doi:10.1016/j.biopha.2015.07.025)

32 Dandona P, Aljada A, Chaudhuri A, Mohanty P \& Garg R. Metabolic syndrome: a comprehensive perspective based on interactions between obesity, diabetes, and inflammation. Circulation 2005111 1448-1454. (doi:10.1161/01.CIR.0000158483.13093.9D)

33 Dandona P, Ghanim H, Chaudhuri A, Dhindsa S \& Kim SS. Macronutrient intake induces oxidative and inflammatory stress: potential relevance to atherosclerosis and insulin resistance. Experimental and Molecular Medicine 201042 245-253. (doi:10.3858/ emm.2010.42.4.033)

34 Lee HS. Impact of maternal diet on the epigenome during in utero life and the developmental programming of diseases in childhood and adulthood. Nutrients 20157 9492-9507. (doi:10.3390/ nu7115467)

35 Barker DJ, Winter PD, Osmond C, Margetts B \& Simmonds SJ. Weight in infancy and death from ischaemic heart disease. Lancet 19892 577-580. (doi:10.1016/S0140-6736(89)90710-1)

36 Barker DJ, Osmond C, Golding J, Kuh D \& Wadsworth ME. Growth in utero, blood pressure in childhood and adult life, and mortality from cardiovascular disease. BMJ 1989298 564-567. (doi:10.1136/ bmj.298.6673.564)

37 Barker DJ. Maternal nutrition, fetal nutrition, and disease in later life. Nutrition 199713 807-813. (doi:10.1016/S0899-9007(97)00193-7)

38 Armitage JA, Taylor PD \& Poston L. Experimental models of developmental programming: consequences of exposure to an energy rich diet during development. Journal of Physiology 2005565 3-8. (doi:10.1113/jphysiol.2004.079756)

39 Gamborg M, Byberg L, Rasmussen F, Andersen PK, Baker JL, Bengtsson C, Canoy D, Droyvold W, Eriksson JG, Forsen T et al. Birth weight and systolic blood pressure in adolescence and adulthood: meta-regression analysis of sex- and age-specific results from 20 Nordic studies. American Journal of Epidemiology 2007166 634-645. (doi:10.1093/aje/kwm042)

40 Thompson LP \& Al-Hasan Y. Impact of oxidative stress in fetal programming. Journal of Pregnancy 20122012582748 (doi:10.1155/2012/582748)

41 Aiken CE, Tarry-Adkins JL, Penfold NC, Dearden L \& Ozanne SE. Decreased ovarian reserve, dysregulation of mitochondrial biogenesis, and increased lipid peroxidation in female mouse offspring exposed to an obesogenic maternal diet. FASEB Journal 201530 1548-1556. (doi:10.1096/fj.15-280800)

42 Saad MI, Abdelkhalek TM, Haiba MM, Saleh MM, Hanafi MY, Tawfik SH \& Kamel MA. Maternal obesity and malnourishment exacerbate perinatal oxidative stress resulting in diabetogenic programming in F1 offspring. Journal of Endocrinological Investigation 201539 643-655. (doi:10.1007/s40618-015-0413-5)

43 Fetoui H, Garoui M \& Zeghal N. Protein restriction in pregnant- and lactating rats-induced oxidative stress and hypohomocysteinaemia in their offspring. Journal of Animal Physiology and Animal Nutrition 200993 263-270. (doi:10.1111/j.1439-0396.2008.00812.x) 
44 Sen S \& Simmons RA. Maternal antioxidant supplementation prevents adiposity in the offspring of Western diet-fed rats. Diabetes 201059 3058-3065. (doi:10.2337/db10-0301)

45 Mohanty P, Hamouda W, Garg R, Aljada A, Ghanim H \& Dandona P. Glucose challenge stimulates reactive oxygen species (ROS) generation by leucocytes. Journal of Clinical Endocrinology and Metabolism 200085 2970-2973. (doi:10.1210/jcem.85.8.6854)

46 Mohanty P, Ghanim H, Hamouda W, Aljada A, Garg R \& Dandona P. Both lipid and protein intakes stimulate increased generation of reactive oxygen species by polymorphonuclear leukocytes and mononuclear cells. American Journal of Clinical Nutrition 200275 767-772.

47 Aljada A, Mohanty P, Ghanim H, Abdo T, Tripathy D, Chaudhuri A $\&$ Dandona P. Increase in intranuclear nuclear factor kappaB and decrease in inhibitor kappaB in mononuclear cells after a mixed meal: evidence for a proinflammatory effect. American Journal of Clinical Nutrition 200479 682-690.

48 Ceriello A \& Motz E. Is oxidative stress the pathogenic mechanism underlying insulin resistance, diabetes, and cardiovascular disease? The common soil hypothesis revisited. Arteriosclerosis Thrombosis and Vascular Biology 200424 816-823. (doi:10.1161/01. ATV.0000122852.22604.78)

49 Wallace JP, Johnson B, Padilla J \& Mather K. Postprandial lipaemia, oxidative stress and endothelial function: a review. International Journal of Clinical Practice 201064 389-403. (doi:10.1111/j.17421241.2009.02146.x)

50 Dandona P, Mohanty P, Ghanim H, Aljada A, Browne R, Hamouda W, Prabhala A, Afzal A \& Garg R. The suppressive effect of dietary restriction and weight loss in the obese on the generation of reactive oxygen species by leukocytes, lipid peroxidation, and protein carbonylation. Journal of Clinical Endocrinology and Metabolism 200186 355-362. (doi:10.1210/jc.86.1.355)

51 Dandona P, Mohanty P, Hamouda W, Ghanim H, Aljada A, Garg R \& Kumar V. Inhibitory effect of a two day fast on reactive oxygen species (ROS) generation by leucocytes and plasma ortho-tyrosine and meta-tyrosine concentrations. Journal of Clinical Endocrinology and Metabolism 200186 2899-2902. (doi:10.1210/jcem.86.6.7745)

52 Rizza W, Veronese N \& Fontana L. What are the roles of calorie restriction and diet quality in promoting healthy longevity? Ageing Research Reviews 201413 38-45. (doi:10.1016/j.arr.2013.11.002)

53 Siri-Tarino PW, Sun Q, Hu FB \& Krauss RM. Saturated fat, carbohydrate, and cardiovascular disease. American Journal of Clinical Nutrition 201091 502-509. (doi:10.3945/ajcn.2008.26285)

54 James MJ, Gibson RA \& Cleland LG. Dietary polyunsaturated fatty acids and inflammatory mediator production. American Journal of Clinical Nutrition 200071 343S-348S.

55 Peairs AD, Rankin JW \& Lee YW. Effects of acute ingestion of different fats on oxidative stress and inflammation in overweight and obese adults. Nutrition Journal 201110 122. (doi:10.1186/14752891-10-122)

56 Teng KT, Chang CY, Chang LF \& Nesaretnam K. Modulation of obesity-induced inflammation by dietary fats: mechanisms and clinica evidence. Nutrition Journal 201413 12. (doi:10.1186/1475-2891-13-12)

57 Dickinson S, Hancock DP, Petocz P, Ceriello A \& Brand-Miller J. High-glycemic index carbohydrate increases nuclear factor-kappaB activation in mononuclear cells of young, lean healthy subjects. American Journal of Clinical Nutrition 200887 1188-1193.

58 Ghanim H, Sia CL, Upadhyay M, Korzeniewski K, Viswanathan P, Abuaysheh S, Mohanty P \& Dandona P. Orange juice neutralizes the proinflammatory effect of a high-fat, high-carbohydrate meal and prevents endotoxin increase and Toll-like receptor expression. American Journal of Clinical Nutrition 201091 940-949. (doi:10.3945/ ajcn.2009.28584)

59 Chiva-Blanch G, Urpi-Sarda M, Llorach R, Rotches-Ribalta M, Guillen M, Casas R, Arranz S, Valderas-Martinez P, Portoles O, Corella D et al. Differential effects of polyphenols and alcohol of red wine on the expression of adhesion molecules and inflammatory cytokines related to atherosclerosis: a randomized clinical trial. American Journal of Clinical Nutrition 201295 326-334. (doi:10.3945/ ajcn.111.022889)

60 Natella F, Belelli F, Gentili V, Ursini F \& Scaccini C. Grape seed proanthocyanidins prevent plasma postprandial oxidative stress in humans. Journal of Agricultural and Food Chemistry $2002 \mathbf{5 0}$ 7720-7725. (doi:10.1021/jf020346o)

61 Ceriello A, Bortolotti N, Motz E, Lizzio S, Catone B, Assaloni R, Tonutti L \& Taboga C. Red wine protects diabetic patients from meal-induced oxidative stress and thrombosis activation: a pleasant approach to the prevention of cardiovascular disease in diabetes. European Journal of Clinical Investigation $200131322-328$. (doi:10.1046/j.1365-2362.2001.00818.x)

62 Bloomer RJ \& Fisher-Wellman KH. Systemic oxidative stress is increased to a greater degree in young, obese women following consumption of a high fat meal. Oxidative Medicine and Cellular Longevity 20092 19-25. (doi:10.4161/oxim.2.1.7860)

63 Goto C, Nishioka K, Umemura T, Jitsuiki D, Sakagutchi A, Kawamura M, Chayama K, Yoshizumi M \& Higashi Y. Acute moderate-intensity exercise induces vasodilation through an increase in nitric oxide bioavailiability in humans. American Journal of Hypertension 200720 825-830. (doi:10.1016/j.amjhyper.2007.02.014)

64 Elosua R, Molina L, Fito M, Arquer A, Sanchez-Quesada JL, Covas MI, Ordonez-Llanos J \& Marrugat J. Response of oxidative stress biomarkers to a 16-week aerobic physical activity program, and to acute physical activity, in healthy young men and women. Atherosclerosis 2003167 327-334. (doi:10.1016/S00219150(03)00018-2)

65 Bloomer RJ, Ferebee DE, Fisher-Wellman KH, Quindry JC \& Schilling BK. Postprandial oxidative stress: influence of sex and exercise training status. Medicine and Science in Sports and Exercise 200941 2111-2119. (doi:10.1249/MSS.0b013e3181a9e832)

66 Uribarri J, Stirban A, Sander D, Cai W, Negrean M, Buenting CE Koschinsky T \& Vlassara H. Single oral challenge by advanced glycation end products acutely impairs endothelial function in diabetic and nondiabetic subjects. Diabetes Care 200730 2579-2582. (doi:10.2337/dc07-0320)

67 Diamanti-Kandarakis E, Katsikis I, Piperi C, Alexandraki K \& Panidis D. Effect of long-term orlistat treatment on serum levels of advanced glycation end-products in women with polycystic ovary syndrome. Clinical Endocrinology 200766 103-109. (doi:10.1111/ j.1365-2265.2006.02693.x)

68 Greenberg AS \& Obin MS. Obesity and the role of adipose tissue in inflammation and metabolism. American Journal of Clinical Nutrition 200683 461S-465S

69 Le Lay S, Simard G, Martinez MC \& Andriantsitohaina R. Oxidative stress and metabolic pathologies: from an adipocentric point of view. Oxidative Medicine and Cellular Longevity 20142014908539. (doi:10.1155/2014/908539)

70 Murphy MP. How mitochondria produce reactive oxygen species. Biochemical Journal 2009417 1-13. (doi:10.1042/BJ20081386)

71 Mahadev K, Motoshima H, Wu X, Ruddy JM, Arnold RS, Cheng G, Lambeth JD \& Goldstein BJ. The NAD(P)H oxidase homolog Nox4 modulates insulin-stimulated generation of $\mathrm{H}_{2} \mathrm{O}_{2}$ and plays an integral role in insulin signal transduction. Molecular and Cellular Biology 200424 1844-1854. (doi:10.1128/MCB.24.5.1844-1854.2004)

72 Han CY, Umemoto T, Omer M, Den Hartigh LJ, Chiba T, LeBoeuf R, Buller CL, Sweet IR, Pennathur S, Abel ED et al. NADPH oxidasederived reactive oxygen species increases expression of monocyte chemotactic factor genes in cultured adipocytes. Journal of Biological Chemistry 2012287 10379-10393. (doi:10.1074/jbc.M111.304998)

73 Elizalde M, Ryden M, van Harmelen V, Eneroth P, Gyllenhammar H, Holm C, Ramel S, Olund A, Arner P \& Andersson K. Expression of nitric oxide synthases in subcutaneous adipose tissue of nonobese and obese humans. Journal of Lipid Research 200041 1244-1251. 
74 May JM \& de Haen C. Insulin-stimulated intracellular hydrogen peroxide production in rat epididymal fat cells. Journal of Biological Chemistry $19792542214-2220$

75 Krieger-Brauer HI, Medda PK \& Kather H. Insulin-induced activation of NADPH-dependent $\mathrm{H}_{2} \mathrm{O}_{2}$ generation in human adipocyte plasma membranes is mediated by Galphai2. Journal of Biological Chemistry 1997272 10135-10143. (doi:10.1074/jbc.272.15.10135)

76 Little SA \& de Haen C. Effects of hydrogen peroxide on basal and hormone-stimulated lipolysis in perifused rat fat cells in relation to the mechanism of action of insulin. Journal of Biological Chemistry 1980255 10888-10895.

77 Herieka M \& Erridge C. High-fat meal induced postprandial inflammation. Molecular Nutrition and Food Research 201458 136-146. (doi:10.1002/mnfr.201300104)

78 Magne J, Mariotti F, Fischer R, Mathe V, Tome D \& Huneau JF. Early postprandial low-grade inflammation after high-fat meal in healthy rats: possible involvement of visceral adipose tissue. Journal of Nutritional Biochemistry 201021 550-555. (doi:10.1016/j. jnutbio.2009.03.004)

79 Travers RL, Motta AC, Betts JA \& Thompson D. Adipose tissue metabolic and inflammatory responses to a mixed meal in lean, overweight and obese men. European Journal of Nutrition 2015. (doi:10.1007/s00394-015-1087-7)

80 Cruz-Teno C, Perez-Martinez P, Delgado-Lista J, Yubero-Serrano EM, Garcia-Rios A, Marin C, Gomez P, Jimenez-Gomez Y, Camargo A, Rodriguez-Cantalejo F et al. Dietary fat modifies the postprandial inflammatory state in subjects with metabolic syndrome: the LIPGENE study. Molecular Nutrition and Food Research 201256 854-865. (doi:10.1002/mnfr.201200096)

81 Meneses ME, Camargo A, Perez-Martinez P, Delgado-Lista J, Cruz-Teno C, Jimenez-Gomez Y, Paniagua JA, Gutierrez-Mariscal FM, Tinahones FJ, Vidal-Puig A et al. Postprandial inflammatory response in adipose tissue of patients with metabolic syndrome after the intake of different dietary models. Molecular Nutrition and Food Research 201155 1759-1770. (doi:10.1002/ mnfr.201100200)

82 Donath MY. Targeting inflammation in the treatment of type 2 diabetes: time to start. Nature Reviews Drug Discovery 201413 465-476. (doi:10.1038/nrd4275)

83 Furukawa S, Fujita T, Shimabukuro M, Iwaki M, Yamada Y, Nakajima Y, Nakayama O, Makishima M, Matsuda M \& Shimomura I. Increased oxidative stress in obesity and its impact on metabolic syndrome. Journal of Clinical Investigation 2004114 1752-1761. (doi:10.1172/jci21625)

84 Murdolo G, Piroddi M, Luchetti F, Tortoioli C, Canonico B, Zerbinati C, Galli F \& Iuliano L. Oxidative stress and lipid peroxidation by-products at the crossroad between adipose organ dysregulation and obesity-linked insulin resistance. Biochimie 2013 95 585-594. (doi:10.1016/j.biochi.2012.12.014)

85 DeFronzo RA, Gunnarsson R, Bjorkman O, Olsson M \& Wahren J. Effects of insulin on peripheral and splanchnic glucose metabolism in noninsulin-dependent (type II) diabetes mellitus. Journal of Clinical Investigation 198576 149-155. (doi:10.1172/JCI111938)

86 Dimitriadis G, Mitrou P, Lambadiari V, Maratou E \& Raptis SA. Insulin effects in muscle and adipose tissue. Diabetes Research and Clinical Practice 201193 (Supplement 1) S52-S59. (doi:10.1016/ S0168-8227(11)70014-6)

87 Galgani JE, Moro C \& Ravussin E. Metabolic flexibility and insulin resistance. American Journal of Physiology: Endocrinology and Metabolism 2008295 E1009-E1017. (doi:10.1152/ajpendo.90558.2008)

88 Corpeleijn E, Saris WH \& Blaak EE. Metabolic flexibility in the development of insulin resistance and type 2 diabetes: effects of lifestyle. Obesity Reviews 200910 178-193. (doi:10.1111/ j.1467-789X.2008.00544.x)

89 Du X, Matsumura T, Edelstein D, Rossetti L, Zsengeller Z, Szabo C $\&$ Brownlee M. Inhibition of GAPDH activity by poly(ADP-ribose) polymerase activates three major pathways of hyperglycemic damage in endothelial cells. Journal of Clinical Investigation 2003 112 1049-1057. (doi:10.1172/JCI18127)

90 Brownlee M. Biochemistry and molecular cell biology of diabetic complications. Nature 2001414 813-820. (doi:10.1038/414813a)

91 Lewis GF, Carpentier A, Adeli K \& Giacca A. Disordered fat storage and mobilization in the pathogenesis of insulin resistance and type 2 diabetes. Endocrine Reviews 200223 201-229. (doi:10.1210/ edrv.23.2.0461)

92 Cooney GJ, Thompson AL, Furler SM, Ye J \& Kraegen EW. Muscle long-chain acyl CoA esters and insulin resistance. Annals of the New York Academy of Sciences 2002967 196-207. (doi:10.1111/j.1749-6632.2002.tb04276.x)

93 Summers SA. Ceramides in insulin resistance and lipotoxicity. Progress in Lipid Research 200645 42-72. (doi:10.1016/j.plipres.2005.11.002)

94 Tumova J, Andel M \& Trnka J. Excess of free fatty acids as a cause of metabolic dysfunction in skeletal muscle. Physiological Research 2015 65 193-207.

95 Itani SI, Ruderman NB, Schmieder F \& Boden G. Lipid-induced insulin resistance in human muscle is associated with changes in diacylglycerol, protein kinase C, and IkappaB-alpha. Diabetes 2002 51 2005-2011. (doi:10.2337/diabetes.51.7.2005)

96 Martins AR, Nachbar RT, Gorjao R, Vinolo MA, Festuccia WT, Lambertucci RH, Cury-Boaventura MF, Silveira LR, Curi R \& Hirabara SM. Mechanisms underlying skeletal muscle insulin resistance induced by fatty acids: importance of the mitochondrial function. Lipids in Health and Disease 201211 30. (doi:10.1186/1476511X-11-30)

97 Yuzefovych LV, Musiyenko SI, Wilson GL \& Rachek LI. Mitochondrial DNA damage and dysfunction, and oxidative stress are associated with endoplasmic reticulum stress, protein degradation and apoptosis in high fat diet-induced insulin resistance mice. PLOS ONE $2013 \mathbf{8}$ e54059. (doi:10.1371/journal.pone.0054059)

98 Wang S \& Kaufman RJ. The impact of the unfolded protein response on human disease. Journal of Cell Biology 2012197 857-867. (doi:10.1083/jcb.201110131)

99 Pagel-Langenickel I, Bao J, Pang L \& Sack MN. The role of mitochondria in the pathophysiology of skeletal muscle insulin resistance. Endocrine Reviews 201031 25-51. (doi:10.1210/er.2009-0003)

100 Abdul-Ghani MA, Muller FL, Liu Y, Chavez AO, Balas B, Zuo P, Chang Z, Tripathy D, Jani R, Molina-Carrion M et al. Deleterious action of FA metabolites on ATP synthesis: possible link between lipotoxicity, mitochondrial dysfunction, and insulin resistance. American Journal of Physiology: Endocrinology and Metabolism 2008 295 E678-E685. (doi:10.1152/ajpendo.90287.2008)

101 Sparks LM, Xie H, Koza RA, Mynatt R, Hulver MW, Bray GA \& Smith SR. A high-fat diet coordinately downregulates genes required for mitochondrial oxidative phosphorylation in skeletal muscle. Diabetes 200554 1926-1933. (doi:10.2337/diabetes.54.7.1926)

102 Muoio DM \& Newgard CB. Mechanisms of disease: molecular and metabolic mechanisms of insulin resistance and beta-cell failure in type 2 diabetes. Nature Reviews Molecular Cell Biology 20089 193-205. (doi:10.1038/nrm2327)

103 Samuel VT, Liu ZX, Qu X, Elder BD, Bilz S, Befroy D, Romanelli AJ $\&$ Shulman GI. Mechanism of hepatic insulin resistance in nonalcoholic fatty liver disease. Journal of Biological Chemistry 2004279 32345-32353. (doi:10.1074/jbc.M313478200)

104 Soardo G, Donnini D, Domenis L, Catena C, De Silvestri D, Cappello D, Dibenedetto A, Carnelutti A, Bonasia V, Pagano C et al. Oxidative stress is activated by free fatty acids in cultured human hepatocytes. Metabolic Syndrome and Related Disorders 20119 397-401. (doi:10.1089/met.2010.0140)

105 Lara-Castro C \& Garvey WT. Intracellular lipid accumulation in liver and muscle and the insulin resistance syndrome. Endocrinology and Metabolism Clinics of North America 200837 841-856. (doi:10.1016/j. ecl.2008.09.002) 
106 Maechler P, Jornot L \& Wollheim CB. Hydrogen peroxide alters mitochondrial activation and insulin secretion in pancreatic beta cells. Journal of Biological Chemistry $199927427905-27913$. (doi:10.1074/jbc.274.39.27905)

107 Tiedge M, Lortz S, Drinkgern J \& Lenzen S. Relation between antioxidant enzyme gene expression and antioxidative defense status of insulin-producing cells. Diabetes 199746 1733-1742. (doi:10.2337/diab.46.11.1733)

108 Nowotny K, Jung T, Hohn A, Weber D \& Grune T. Advanced glycation end products and oxidative stress in type 2 diabetes mellitus. Biomolecules 20155 194-222. (doi:10.3390/biom5010194)

109 Jacqueminet S, Briaud I, Rouault C, Reach G \& Poitout V. Inhibition of insulin gene expression by long-term exposure of pancreatic beta cells to palmitate is dependent on the presence of a stimulatory glucose concentration. Metabolism 200049 532-536. (doi:10.1016/ S0026-0495(00)80021-9)

110 Sakai K, Matsumoto K, Nishikawa T, Suefuji M, Nakamaru K, Hirashima Y, Kawashima J, Shirotani T, Ichinose K, Brownlee M et al. Mitochondrial reactive oxygen species reduce insulin secretion by pancreatic beta-cells. Biochemical and Biophysical Research Communications 2003300 216-222. (doi:10.1016/S0006291X(02)02832-2)

111 Ding EL, Song Y, Malik VS \& Liu S. Sex differences of endogenous sex hormones and risk of type 2 diabetes: a systematic review and meta-analysis. JAMA 2006295 1288-1299. (doi:10.1001/ jama.295.11.1288)

112 Gupte AA, Pownall HJ \& Hamilton DJ. Estrogen: an emerging regulator of insulin action and mitochondrial function. Journal of Diabetes Research 20152015 916585. (doi:10.1155/2015/916585)

113 Hewitt SC \& Korach KS. Estrogen receptors: structure, mechanisms and function. Reviews in Endocrine and Metabolic Disorders 20023 193-200. (doi:10.1023/A:1020068224909)

114 Barros RP, Gabbi C, Morani A, Warner M \& Gustafsson JA. Participation of ERalpha and ERbeta in glucose homeostasis in skeletal muscle and white adipose tissue. American Journal of Physiology: Endocrinology and Metabolism 2009297 E124-E133. (doi:10.1152/ajpendo.00189.2009)

115 Cavalcanti-de-Albuquerque JP, Salvador IC, Martins EL, JardimMesseder D, Werneck-de-Castro JP, Galina A \& Carvalho DP. Role of estrogen on skeletal muscle mitochondrial function in ovariectomized rats: a time course study in different fiber types. Journal of Applied Physiology (1985) 2014116 779-789. (doi:10.1152/ japplphysiol.00121.2013)

116 Zhu L, Martinez MN, Emfinger CH, Palmisano BT \& Stafford JM. Estrogen signaling prevents diet-induced hepatic insulin resistance in male mice with obesity. American Journal of Physiology: Endocrinology and Metabolism 2014306 E1188-E1197. (doi:10.1152/ajpcell.00096.2013)

117 Liu S \& Mauvais-Jarvis F. Minireview: estrogenic protection of betacell failure in metabolic diseases. Endocrinology $2010151859-864$. (doi:10.1210/en.2009-1107)

118 Duckles SP, Krause DN, Stirone C \& Procaccio V. Estrogen and mitochondria: a new paradigm for vascular protection? Molecular Interventions 20066 26-35. (doi:10.1124/mi.6.1.6)

119 O'Lone R, Knorr K, Jaffe IZ, Schaffer ME, Martini PG, Karas RH, Bienkowska J, Mendelsohn ME \& Hansen U. Estrogen receptors alpha and beta mediate distinct pathways of vascular gene expression, including genes involved in mitochondrial electron transport and generation of reactive oxygen species. Molecular Endocrinology 200721 1281-1296. (doi:10.1210/me.2006-0497)

120 Mattingly KA, Ivanova MM, Riggs KA, Wickramasinghe NS, Barch MJ \& Klinge CM. Estradiol stimulates transcription of nuclear respiratory factor-1 and increases mitochondrial biogenesis. Molecular Endocrinology 200822 609-622. (doi:10.1210/me.2007-0029)

121 Sanchez MI, Shearwood AM, Chia T, Davies SM, Rackham O \& Filipovska A. Estrogen-mediated regulation of mitochondrial gene expression. Molecular Endocrinology 201529 14-27. (doi:10.1210/ me.2014-1077)

122 Moghetti P, Tosi F, Castello R, Magnani CM, Negri C, Brun E, Furlani L, Caputo M \& Muggeo M. The insulin resistance in women with hyperandrogenism is partially reversed by antiandrogen treatment: evidence that androgens impair insulin action in women. Journal of Clinical Endocrinology and Metabolism 199681 952-960. (doi:10.1210/jc.81.3.952)

123 Diamanti-Kandarakis E, Mitrakou A, Hennes MM, Platanissiotis D, Kaklas N, Spina J, Georgiadou E, Hoffmann RG, Kissebah AH \& Raptis S. Insulin sensitivity and antiandrogenic therapy in women with polycystic ovary syndrome. Metabolism $1995 \mathbf{4 4} 525-531$. (doi:10.1016/0026-0495(95)90062-4)

124 Diamanti-Kandarakis E, Mitrakou A, Raptis S, Tolis G \& Duleba AJ. The effect of a pure antiandrogen receptor blocker, flutamide, on the lipid profile in the polycystic ovary syndrome. Journal of Clinical Endocrinology and Metabolism 199883 2699-2705. (doi:10.1210/ jcem.83.8.5041)

125 Liu S, Navarro G \& Mauvais-Jarvis F. Androgen excess produces systemic oxidative stress and predisposes to beta-cell failure in female mice. PLoS ONE 20105 e11302. (doi:10.1371/journal. pone.0011302)

126 Fagman JB, Wilhelmson AS, Motta BM, Pirazzi C, Alexanderson C, De Gendt K, Verhoeven G, Holmang A, Anesten F, Jansson JO et al. The androgen receptor confers protection against diet-induced atherosclerosis, obesity, and dyslipidemia in female mice. FASEB Journal 201529 1540-1550. (doi:10.1096/fj.14-259234)

127 Ide T, Tsutsui H, Ohashi N, Hayashidani S, Suematsu N, Tsuchihashi M, Tamai H \& Takeshita A. Greater oxidative stress in healthy young men compared with premenopausal women. Arteriosclerosis Thrombosis and Vascular Biology 200222 438-442. (doi:10.1161/hq0302.104515)

128 Bloomer RJ \& Fisher-Wellman KH. Lower postprandial oxidative stress in women compared with men. Gender Medicine 20107 340-349. (doi:10.1016/j.genm.2010.07.001)

129 Nickelson KJ, Stromsdorfer KL, Pickering RT, Liu TW, Ortinau LC, Keating AF \& Perfield JW 2nd. A comparison of inflammatory and oxidative stress markers in adipose tissue from weight-matched obese male and female mice. Experimental Diabetes Research 2012 2012 859395. (doi:10.1155/2012/859395)

130 Stubbins RE, Najjar K, Holcomb VB, Hong J \& Nunez NP. Oestrogen alters adipocyte biology and protects female mice from adipocyte inflammation and insulin resistance. Diabetes, Obesity and Metabolism 201214 58-66. (doi:10.1111/j.14631326.2011.01488.x)

131 te Velde ER \& Pearson PL. The variability of female reproductive ageing. Human Reproduction Update 20028 141-154. (doi:10.1093/ humupd/8.2.141)

132 Doshi SB \& Agarwal A. The role of oxidative stress in menopause. Journal of Midlife Health 20134 140-146. (doi:10.4103/09767800.118990)

133 Ogunro PS, Bolarinde AA, Owa OO, Salawu AA \& Oshodi AA. Antioxidant status and reproductive hormones in women during reproductive, perimenopausal and postmenopausal phase of life. African Journal of Medical and Health Sciences 2014 43 49-57.

134 Zitnanova I, Rakovan M, Paduchova Z, Dvorakova M, Andrezalova L, Muchova J, Simko M, Waczulikova I \& Durackova Z. Oxidative stress in women with perimenopausal symptoms. Menopause $2011 \mathbf{1 8}$ 1249-1255. (doi:10.1097/gme.0b013e318224fa3d)

135 Bellanti F, Matteo M, Rollo T, De Rosario F, Greco P, Vendemiale G \& Serviddio G. Sex hormones modulate circulating antioxidant enzymes: impact of estrogen therapy. Redox Biology 20131 340-346. (doi:10.1016/j.redox.2013.05.003)

136 Unfer TC, Figueiredo CG, Zanchi MM, Maurer LH, Kemerich DM, Duarte MM, Konopka CK \& Emanuelli T. Estrogen plus progestin 
increase superoxide dismutase and total antioxidant capacity in postmenopausal women. Climacteric 201518 379-388. (doi:10.3109/ 13697137.2014.964669)

137 Moreau KL \& Hildreth KL. Vascular aging across the menopause transition in healthy women. Advances in Vascular Medicine 2014. (doi:10.1155/2014/204390)

138 Busserolles J, Mazur A, Gueux E, Rock E \& Rayssiguier Y. Metabolic syndrome in the rat: females are protected against the pro-oxidant effect of a high sucrose diet. Experimental Biology and Medicine 2002 227 837-842.

139 Sankar P, Zachariah B, Vickneshwaran V, Jacob SE \& Sridhar MG. Amelioration of oxidative stress and insulin resistance by soy isoflavones (from Glycine max) in ovariectomized Wistar rats fed with high fat diet: the molecular mechanisms. Experimental Gerontology 201563 67-75. (doi:10.1016/j.exger.2015.02.001)

140 Camporez JP, Jornayvaz FR, Lee HY, Kanda S, Guigni BA, Kahn M, Samuel VT, Carvalho CR, Petersen KF, Jurczak MJ et al. Cellular mechanism by which estradiol protects female ovariectomized mice from high-fat diet-induced hepatic and muscle insulin resistance. Endocrinology 2013154 1021-1028. (doi:10.1210/en.2012-1989)

141 Pentti K, Tuppurainen MT, Honkanen R, Sandini L, Kroger H, Alhava E \& Saarikoski S. Hormone therapy protects from diabetes: the Kuopio osteoporosis risk factor and prevention study. European Journal of Endocrinology 2009160 979-983. (doi:10.1530/EJE-09-0151)

142 Szmuilowicz ED, Stuenkel CA \& Seely EW. Influence of menopause on diabetes and diabetes risk. Nature Reviews Endocrinology 20095 553-558. (doi:10.1038/nrendo.2009.166)

143 Behrman HR, Kodaman PH, Preston SL \& Gao S. Oxidative stress and the ovary. Journal of the Society for Gynecologic Investigation $2001 \mathbf{8}$ S40-S42. (doi:10.1016/S1071-5576(00)00106-4)

144 Miesel R, Drzejczak PJ \& Kurpisz M. Oxidative stress during the interaction of gametes. Biology of Reproduction 199349 918-923. (doi:10.1095/biolreprod49.5.918)

145 Guerin P, El Mouatassim S \& Menezo Y. Oxidative stress and protection against reactive oxygen species in the pre-implantation embryo and its surroundings. Human Reproduction Update 20017 175-189. (doi:10.1093/humupd/7.2.175)

146 Ruder EH, Hartman TJ, Blumberg J \& Goldman MB. Oxidative stress and antioxidants: exposure and impact on female fertility. Human Reproduction Update 200814 345-357. (doi:10.1093/humupd/dmn011)

147 Nunez-Calonge R, Cortes S, Gutierrez Gonzalez LM, Kireev R, Vara E, Ortega L, Caballero P, Rancan L \& Tresguerres J. Oxidative stress in follicular fluid of young women with low response compared with fertile oocyte donors. Reproductive Biomedicine Online 201632 446-456. (doi:10.1016/j.rbmo.2015.12.010)

148 Das S, Chattopadhyay R, Ghosh S, Ghosh S, Goswami SK, Chakravarty BN \& Chaudhury K. Reactive oxygen species level in follicular fluid - embryo quality marker in IVF? Human Reproduction 200621 2403-2407. (doi:10.1093/humrep/del156)

149 Singh AK, Chattopadhyay R, Chakravarty B \& Chaudhury K. Markers of oxidative stress in follicular fluid of women with endometriosis and tubal infertility undergoing IVF. Reproductive Toxicology 201342 116-124. (doi:10.1016/j.reprotox.2013.08.005)

150 Pasqualotto EB, Agarwal A, Sharma RK, Izzo VM, Pinotti JA, Joshi NJ $\&$ Rose BI. Effect of oxidative stress in follicular fluid on the outcome of assisted reproductive procedures. Fertility and Sterility $2004 \mathbf{8 1}$ 973-976. (doi:10.1016/j.fertnstert.2003.11.021)

151 Bedaiwy MA, Elnashar SA, Goldberg JM, Sharma R, Mascha EJ, Arrigain S, Agarwal A \& Falcone T. Effect of follicular fluid oxidative stress parameters on intracytoplasmic sperm injection outcome. Gynecological Endocrinology 201228 51-55. (doi:10.3109/09513590.2 $011.579652)$

152 Velthut A, Zilmer M, Zilmer K, Kaart T, Karro H \& Salumets A. Elevated blood plasma antioxidant status is favourable for achieving IVF/ICSI pregnancy. Reproductive Biomedicine Online 201326 345-352. (doi:10.1016/j.rbmo.2012.12.012)
153 Valckx SD, Van Hoeck V, Arias-Alvarez M, Maillo V, Lopez Cardona AP, Gutierrez-Adan A, Berth M, Cortvrindt R, Bols PE \& Leroy JL. Elevated non-esterified fatty acid concentrations during in vitro murine follicle growth alter follicular physiology and reduce oocyte developmental competence. Fertility and Sterility 2014102 1769.e1761-1776.e1761. (doi:10.1016/j.fertnstert.2014.08.018)

154 Kazemi A, Ramezanzadeh F, Nasr-Esfahani MH, Saboor Yaraghi AA \& Ahmadi M. Does dietary fat intake influence oocyte competence and embryo quality by inducing oxidative stress in follicular fluid? Iranian Journal of Reproductive Medicine 201311 1005-1012.

155 Kazemi A, Ramezanzadeh F, Nasr-Esfahani MH, Saboor-Yaraghi AA, Nejat SN \& Rahimi-Foroshani A. Relationship between energy expenditure related factors and oxidative stress in follicular fluid. International journal of Fertility and Sterility 20148 175-182.

156 Tatone C, Eichenlaub-Ritter U \& Amicarelli F. Dicarbonyl stress and glyoxalases in ovarian function. Biochemical Society Transactions 2014 42 433-438. (doi:10.1042/BST20140023)

157 Merhi Z. Advanced glycation end products and their relevance in female reproduction. Human Reproduction 201429 135-145. (doi:10.1093/humrep/det383)

158 Jinno M, Takeuchi M, Watanabe A, Teruya K, Hirohama J, Eguchi N \& Miyazaki A. Advanced glycation end-products accumulation compromises embryonic development and achievement of pregnancy by assisted reproductive technology. Human Reproduction 201126 604-610. (doi:10.1093/humrep/deq388)

159 Malickova K, Jarosova R, Rezabek K, Fait T, Masata J, Janatkova I, Zima T \& Kalousova M. Concentrations of sRAGE in serum and follicular fluid in assisted reproductive cycles - a preliminary study. Clinical Laboratory 201056 377-384.

160 Merhi Z, Irani M, Doswell AD \& Ambroggio J. Follicular fluid soluble receptor for advanced glycation end-products (sRAGE): a potential indicator of ovarian reserve. Journal of Clinical Endocrinology and Metabolism 201499 E226-E233. (doi:10.1210/jc.2013-3839)

161 Broekmans FJ, Soules MR \& Fauser BC. Ovarian aging: mechanisms and clinical consequences. Endocrine Reviews $200930465-493$. (doi:10.1210/er.2009-0006)

162 Tatone C, Amicarelli F, Carbone MC, Monteleone P, Caserta D, Marci R, Artini PG, Piomboni P \& Focarelli R. Cellular and molecular aspects of ovarian follicle ageing. Human Reproduction Update 2008 14 131-142. (doi:10.1093/humupd/dmm048)

163 Signorelli SS, Neri S, Sciacchitano S, Pino LD, Costa MP, Marchese G, Celotta G, Cassibba N, Pennisi G \& Caschetto S. Behaviour of some indicators of oxidative stress in postmenopausal and fertile women. Maturitas 200653 77-82. (doi:10.1016/ j.maturitas.2005.03.001)

164 Van Blerkom J. The influence of intrinsic and extrinsic factors on the developmental potential and chromosomal normality of the human oocyte. Journal of the Society for Gynecologic Investigation 19963 3-11. (doi:10.1016/1071-5576(95)00041-0)

165 Carbone MC, Tatone C, Delle Monache S, Marci R, Caserta D, Colonna R \& Amicarelli F. Antioxidant enzymatic defences in human follicular fluid: characterization and age-dependent changes. Molecular Human Reproduction 20039 639-643. (doi:10.1093/molehr/gag090)

166 Lim J \& Luderer U. Oxidative damage increases and antioxidant gene expression decreases with aging in the mouse ovary. Biology of Reproduction 201184 775-782. (doi:10.1095/biolreprod.110.088583)

167 Wang Z, Chandrasena ER, Yuan Y, Peng KW, van Breemen RB, Thatcher GR \& Bolton JL. Redox cycling of catechol estrogens generating apurinic/apyrimidinic sites and 8-oxo-deoxyguanosine via reactive oxygen species differentiates equine and human estrogens. Chemical Research in Toxicology 201023 1365-1373. (doi:10.1021/tx1001282)

168 Diamanti-Kandarakis E, Piperi C, Patsouris E, Korkolopoulou P, Panidis D, Pawelczyk L, Papavassiliou AG \& Duleba AJ. Immunohistochemical localization of advanced glycation endproducts (AGEs) and their receptor (RAGE) in polycystic and 
normal ovaries. Histochemistry and Cell Biology 2007127 581-589. (doi:10.1007/s00418-006-0265-3)

169 Papachroni KK, Piperi C, Levidou G, Korkolopoulou P, Pawelczyk L, Diamanti-Kandarakis E \& Papavassiliou AG. Lysyl oxidase interacts with AGE signalling to modulate collagen synthesis in polycystic ovarian tissue. Journal of Cellular and Molecular Medicine 201014 2460-2469. (doi:10.1111/j.1582-4934.2009.00841.x)

170 Stensen MH, Tanbo T, Storeng R \& Fedorcsak P. Advanced glycation end products and their receptor contribute to ovarian ageing. Human Reproduction 201429 125-134. (doi:10.1093/humrep/det419)

171 Tatone C, Carbone MC, Campanella G, Festuccia C, Artini PG, Talesa V, Focarelli R \& Amicarelli F. Female reproductive dysfunction during ageing: role of methylglyoxal in the formation of advanced glycation endproducts in ovaries of reproductively-aged mice. Journal of Biological Regulators and Homeostatic Agents 201024 63-72.

172 Polak G, Koziol-Montewka M, Gogacz M, Blaszkowska I \& Kotarski J. Total antioxidant status of peritoneal fluid in infertile women. European Journal of Obstetrics and Gynecology and Reproductive Biology 200194 261-263. (doi:10.1016/S0301-2115(00)00352-3)

173 Wang Y, Sharma RK, Falcone T, Goldberg J \& Agarwal A. Importance of reactive oxygen species in the peritoneal fluid of women with endometriosis or idiopathic infertility. Fertility and Sterility 199768 826-830. (doi:10.1016/S0015-0282(97)00343-9)

174 Badawy A, Baker El Nashar A \& El Totongy M. Clomiphene citrate plus $\mathrm{N}$-acetyl cysteine versus clomiphene citrate for augmenting ovulation in the management of unexplained infertility: a randomized double-blind controlled trial. Fertility and Sterility 2006 86 647-650. (doi:10.1016/j.fertnstert.2006.02.097)

175 Diamanti-Kandarakis E, Kouli CR, Bergiele AT, Filandra FA, Tsianateli TC, Spina GG, Zapanti ED \& Bartzis MI. A survey of the polycystic ovary syndrome in the Greek island of Lesbos: hormonal and metabolic profile. Journal of Clinical Endocrinology and Metabolism 199984 4006-4011. (doi:10.1210/jcem.84.11.6148)

176 Diamanti-Kandarakis E \& Dunaif A. Insulin resistance and the polycystic ovary syndrome revisited: an update on mechanisms and implications. Endocrine Reviews 201233 981-1030. (doi:10.1210/ er.2011-1034)

177 Duleba AJ \& Dokras A. Is PCOS an inflammatory process? Fertility and Sterility 201297 7-12. (doi:10.1016/j.fertnstert.2011.11.023)

178 Hyderali BN \& Mala K. Oxidative stress and cardiovascular complications in polycystic ovarian syndrome. European Journal of Obstetrics and Gynecology and Reproductive Biology 2015191 15-22. (doi:10.1016/j.ejogrb.2015.05.005)

179 Papalou O, Victor VM \& Diamanti-Kandaraki E. Oxidative stress in polycystic ovary syndrome. Current Pharmaceutical Design 201622 2709-2722. (doi:10.2174/1381612822666160216151852)

180 Murri M, Luque-Ramirez M, Insenser M, Ojeda-Ojeda M \& EscobarMorreale HF. Circulating markers of oxidative stress and polycystic ovary syndrome (PCOS): a systematic review and meta-analysis. Human Reproduction Update 201319 268-288. (doi:10.1093/humupd/dms059)

181 Moti M, Amini L, Mirhoseini Ardakani SS, Kamalzadeh S, Masoomikarimi M \& Jafarisani M. Oxidative stress and anti-oxidant defense system in Iranian women with polycystic ovary syndrome. Iranian Journal of Reproductive Medicine 201513 373-378.

182 Blair SA, Kyaw-Tun T, Young IS, Phelan NA, Gibney J \& McEneny J. Oxidative stress and inflammation in lean and obese subjects with polycystic ovary syndrome. Journal of Reproductive Medicine $2013 \mathbf{5 8}$ 107-114.

183 Baskol G, Aygen E, Erdem F, Caniklioglu A, Narin F, Sahin Y \& Kaya T. Assessment of paraoxonase 1, xanthine oxidase and glutathione peroxidase activities, nitric oxide and thiol levels in women with polycystic ovary syndrome. Acta Obstetricia et Gynecologica Scandinavica 201291 326-330. (doi:10.1111/j.16000412.2011.01337.x)

184 Marsillach J, Checa MA, Pedro-Botet J, Carreras R, Joven J \& Camps J. Paraoxonase-1 in female infertility: a possible role against oxidative stress-induced inflammation. Fertility and Sterility 201094 1132-1134. (doi:10.1016/j.fertnstert.2009.11.043)

185 Gonzalez F, Rote NS, Minium J \& Kirwan JP. Reactive oxygen species-induced oxidative stress in the development of insulin resistance and hyperandrogenism in polycystic ovary syndrome. Journal of Clinical Endocrinology and Metabolism 200691 336-340. (doi:10.1210/jc.2005-1696)

186 Gonzalez F, Sia CL, Shepard MK, Rote NS \& Minium J. Hyperglycemia-induced oxidative stress is independent of excess abdominal adiposity in normal-weight women with polycystic ovary syndrome. Human Reproduction 201227 3560-3568. (doi:10.1093/ humrep/des320)

187 Savic-Radojevic A, Bozic Antic I, Coric V, Bjekic-Macut J, Radic T, Zarkovic M, Djukic T, Pljesa-Ercegovac M, Panidis D, Katsikis I et al. Effect of hyperglycemia and hyperinsulinemia on glutathione peroxidase activity in non-obese women with polycystic ovary syndrome. Hormones 201514 101-108. (doi:10.14310/ horm.2002.1525)

188 Gonzalez F, Nair KS, Daniels JK, Basal E \& Schimke JM. Hyperandrogenism sensitizes mononuclear cells to promote glucoseinduced inflammation in lean reproductive-age women. American Journal of Physiology: Endocrinology and Metabolism 2012302 E297-E306. (doi:10.1152/ajpendo.00416.2011)

189 Gonzalez F, Nair KS, Daniels JK, Basal E, Schimke JM \& Blair HE. Hyperandrogenism sensitizes leukocytes to hyperglycemia to promote oxidative stress in lean reproductive-age women. Journal of Clinical Endocrinology and Metabolism 201297 2836-2843. (doi:10.1210/jc.2012-1259)

190 Malin SK, Kirwan JP, Sia CL \& Gonzalez F. Glucose-stimulated oxidative stress in mononuclear cells is related to pancreatic betacell dysfunction in polycystic ovary syndrome. Journal of Clinical Endocrinology and Metabolism 201499 322-329. (doi:10.1210/ jc.2013-3177)

191 Malin SK, Kirwan JP, Sia CL \& Gonzalez F. Pancreatic beta-cell dysfunction in polycystic ovary syndrome: role of hyperglycemiainduced nuclear factor-kappaB activation and systemic inflammation. American Journal of Physiology: Endocrinology and Metabolism 2015308 E770-E777. (doi:10.1152/ajpendo.00510.2014)

192 Chattopadhayay R, Ganesh A, Samanta J, Jana SK, Chakravarty BN $\&$ Chaudhury K. Effect of follicular fluid oxidative stress on meiotic spindle formation in infertile women with polycystic ovarian syndrome. Gynecologic and Obstetric Investigation 201069 197-202. (doi:10.1159/000270900)

193 Qiao J \& Feng HL. Extra- and intra-ovarian factors in polycystic ovary syndrome: impact on oocyte maturation and embryo developmental competence. Human Reproduction Update 201117 17-33. (doi:10.1093/humupd/dmq032)

194 Karuputhula NB, Chattopadhyay R, Chakravarty B \& Chaudhury K. Oxidative status in granulosa cells of infertile women undergoing IVF. Systems Biology in Reproductive Medicine 201359 91-98. (doi:10.3 109/19396368.2012.743197)

195 Rezvanfar MA, Shojaei Saadi HA, Gooshe M, Abdolghaffari AH, Baeeri M \& Abdollahi M. Ovarian aging-like phenotype in the hyperandrogenism-induced murine model of polycystic ovary. Oxidative Medicine and Cellular Longevity 20142014948951. (doi:10.1155/2014/948951)

196 Tehrani FR, Solaymani-Dodaran M, Hedayati M \& Azizi F. Is polycystic ovary syndrome an exception for reproductive aging? Human Reproduction 201025 1775-1781. (doi:10.1093/humrep/ deq088)

197 Welt CK \& Carmina E. Clinical review: lifecycle of polycystic ovary syndrome (PCOS): from in utero to menopause. Journal of Clinical Endocrinology and Metabolism 201398 4629-4638. (doi:10.1210/ jc.2013-2375)

198 Diamanti-Kandarakis E, Katsikis I, Piperi C, Kandaraki E, Piouka A, Papavassiliou AG \& Panidis D. Increased serum advanced glycation 
end-products is a distinct finding in lean women with polycystic ovary syndrome (PCOS). Clinical Endocrinology 200869 634-641. (doi:10.1111/j.1365-2265.2008.03247.x)

199 Diamanti-Kandarakis E, Piouka A, Livadas S, Piperi C, Katsikis I, Papavassiliou AG \& Panidis D. Anti-mullerian hormone is associated with advanced glycosylated end products in lean women with polycystic ovary syndrome. European Journal of Endocrinology 2009 160 847-853. (doi:10.1530/EJE-08-0510)

200 Diamanti-Kandarakis E, Piperi C, Korkolopoulou P, Kandaraki E, Levidou G, Papalois A, Patsouris E \& Papavassiliou AG. Accumulation of dietary glycotoxins in the reproductive system of normal female rats. Journal of Molecular Medicine 200785 1413-1420. (doi:10.1007/s00109-007-0246-6)

201 Kandaraki E, Chatzigeorgiou A, Piperi C, Palioura E, Palimeri S, Korkolopoulou P, Koutsilieris M \& Papavassiliou AG. Reduced ovarian glyoxalase-I activity by dietary glycotoxins and androgen excess: a causative link to polycystic ovarian syndrome. Molecular Medicine 201218 1183-1189. (doi:10.2119/molmed.2012.00293)

202 Diamanti-Kandarakis E, Chatzigeorgiou A, Papageorgiou E, Koundouras D \& Koutsilieris M. Advanced glycation end-products and insulin signaling in granulosa cells. Experimental Biology and Medicine 2015241 1438-1445. (doi:10.1177/1535370215584937)

203 Cai W, Ramdas M, Zhu L, Chen X, Striker GE \& Vlassara H. Oral advanced glycation endproducts (AGEs) promote insulin resistance and diabetes by depleting the antioxidant defenses AGE receptor-1 and sirtuin 1. PNAS 2012109 15888-15893. (doi:10.1073/ pnas.1205847109)

204 Tantalaki E, Piperi C, Livadas S, Kollias A, Adamopoulos C, Koulouri A, Christakou C \& Diamanti-Kandarakis E. Impact of dietary modification of advanced glycation end products (AGEs) on the hormonal and metabolic profile of women with polycystic ovary syndrome (PCOS). Hormones 201413 65-73.

205 Iwabuchi T, Yoshimoto C, Shigetomi H \& Kobayashi H. Oxidative stress and antioxidant defense in endometriosis and its malignant transformation. Oxidative Medicine and Cellular Longevity 20152015 848595. (doi:10.1155/2015/848595)

206 Rong R, Ramachandran S, Santanam N, Murphy AA \& Parthasarathy S. Induction of monocyte chemotactic protein-1 in peritoneal mesothelial and endometrial cells by oxidized low-density lipoprotein and peritoneal fluid from women with endometriosis. Fertility and Sterility 200278 843-848. (doi:10.1016/S00150282(02)03333-2)

207 Prieto L, Quesada JF, Cambero O, Pacheco A, Pellicer A, Codoceo R $\&$ Garcia-Velasco JA. Analysis of follicular fluid and serum markers of oxidative stress in women with infertility related to endometriosis. Fertility and Sterility 201298 126-130. (doi:10.1016/j. fertnstert.2012.03.052)

208 Choi YS, Cho S, Seo SK, Park JH, Kim SH \& Lee BS. Alteration in the intrafollicular thiol-redox system in infertile women with endometriosis. Reproduction 2015149 155-162. (doi:10.1530/ REP-14-0438)

209 Mier-Cabrera J, Aburto-Soto T, Burrola-Mendez S, JimenezZamudio L, Tolentino MC, Casanueva E \& HernandezGuerrero C. Women with endometriosis improved their peripheral antioxidant markers after the application of a high antioxidant diet. Reproductive Biology and Endocrinology 2009754. (doi:10.1186/1477-7827-7-54)

210 Heilbronn LK, de Jonge L, Frisard MI, DeLany JP, Larson-Meyer DE, Rood J, Nguyen T, Martin CK, Volaufova J, Most MM et al. Effect of 6-month calorie restriction on biomarkers of longevity, metabolic adaptation, and oxidative stress in overweight individuals: a randomized controlled trial. JAMA 2006295 1539-1548. (doi:10.1001/jama.295.13.1539)

211 Ceriello A, Esposito K, La Sala L, Pujadas G, De Nigris V, Testa R, Bucciarelli L, Rondinelli M \& Genovese $\mathrm{S}$. The protective effect of the Mediterranean diet on endothelial resistance to GLP-1 in type 2 diabetes: a preliminary report. Cardiovascular Diabetology 201413 140. (doi:10.1186/s12933-014-0140-9)

Received 24 July 2016

Revised version received 20 September 2016

Accepted 27 September 2016 